\title{
The Dark Side of Development:
} A Systems Characterization of the Negative Mentoring Experiences of Doctoral Students

Trevor T. Tuma, ${ }^{\ddagger}$ John D. Adams, ${ }^{\ddagger}$ Benjamin C. Hultquist, ${ }^{*}$ and Erin L. Dolan ${ }^{\ddagger *}$

${ }^{t}$ Department of Plant Biology and "Department of Biochemistry \& Molecular Biology, University of Georgia, Athens, GA 30602

\begin{abstract}
Effective mentoring promotes the development and success of graduate students. Yet mentoring, like other relationships, can have negative elements. Little knowledge exists about the problematic mentoring that graduate students experience despite its potentially detrimental impacts. To begin to address this gap, we conducted an exploratory interview study to define and characterize negative mentoring experiences of 40 life science doctoral students. Students attributed their negative mentoring experiences to interacting factors at multiple levels-from interpersonal differences and poor relationship quality to issues at the research group, departmental, organizational, and discipline levels-all of which they perceived as harmful to their development. We found that doctoral students experienced forms of negative mentoring similar to those reported in workplace and undergraduate research settings, but they also experienced negative mentoring that was unique to academic research and their stage of development. Our results are useful to mentors for reflecting on ways their behaviors might be perceived, to mentees for avoiding situations that might be conducive to negative mentoring, and to programs and institutions for improving structures and processes to prevent negative mentoring. Our findings also serve as a foundation for future research on the prevalence and impacts of negative mentoring experiences in graduate education.
\end{abstract}

\section{INTRODUCTION}

Graduate education in science, technology, engineering, and mathematics (STEM) fields in the United States prepares professionals who contribute substantively to the national and global economy, environment, security, and health. The U.S. higher education system consistently remains the largest destination in the world for students to pursue graduate education (National Academies of Sciences, Engineering, and Medicine [NASEM], 2018). Over the past decade, STEM graduate education has received increased attention due to high rates of attrition and growing concern over deteriorating graduate student well-being (Sowell et al., 2015; Levecque et al., 2017). For example, attrition from STEM doctoral programs has remained alarmingly high, with more than $50 \%$ of students leaving before completing their intended degree (Golde, 1998; Lovitts, 2002; Sowell et al., 2015). Equally concerning are recent findings that the majority of graduate students report significantly higher levels of stress, burnout, substance use, and mental health problems (e.g., anxiety, depression) than the general population (Hyun et al., 2006; Levecque et al., 2017; Evans et al., 2018; Hish et al., 2019; Nagy et al., 2019; Allen et al., 2020). As a result, there is a growing interest in identifying and addressing the factors that lead to these undesirable outcomes (NASEM, 2018).

In response, NASEM reports (2018) have called for systemic changes to STEM graduate education with a high priority being improved mentoring relationships and
Graham Hatfull, Monitoring Editor

Submitted Oct 6, 2020; Revised Jan 8, 2021; Accepted Jan 15, 2021

CBE Life Sci Educ June 1, 2021 20:ar16

DOI:10.1187/cbe.20-10-0231

*Address correspondence to: Erin L. Dolan (eldolan@uga.edu).

() 2021 T. T. Tuma et al. CBE-Life Sciences Education @ 2021 The American Society for Cell Biology. This article is distributed by The American Society for Cell Biology under license from the author(s). It is available to the public under an Attribution-Noncommercial-Share Alike 3.0 Unported Creative Commons License (http://creativecommons.org/licenses/ by-nc-sa/3.0)

"ASCB®" and "The American Society for Cell Biology ${ }^{\circledR} "$ are registered trademarks of The American Society for Cell Biology. 
practices. Mentorship has most recently been defined as a professional, working alliance in which a more experienced individual (the mentor) acts as a guide, role model, and sponsor to support the personal and professional growth, development, and success of a less experienced individual (the mentee; NASEM, 2019). Mentors provide career support (e.g., career guidance, sponsorship, advancement) and psychosocial support (e.g., counseling, encouragement, role modeling, acceptance) to mentees, which increases the quality of and satisfaction with the mentoring relationship and can improve the outcomes realized by both mentees and mentors (Eby et al., 2013; NASEM, 2019).

In most STEM fields, a principal investigator (PI) of a research group or a faculty advisor is responsible for guiding and supervising the work of graduate students during their graduate research, with an implicit expectation that the faculty member is a mentor to the graduate student mentee. There is ongoing debate about whether the working relationship between a doctoral advisor and doctoral student is truly a "mentoring" relationship, because not all faculty are viewed as or rewarded for acting as mentors to their students. This distinction is significant, because a mentor provides ongoing support and develops a deeper personal relationship, while an advisor provides practical guidance for completing degree requirements and improving content knowledge, in addition to acting as a role model (Eby and Dolan, 2015; NASEM 2018). The difference between an advisor or supervisor and a mentor has empirically been demonstrated to be distinct for employees in the workplace (Sosik and Godshalk, 2000; Ragins et al., 2017), suggesting that mentoring provides important forms of support that an advising relationship likely will not. While the role of faculty members during graduate education has remained contentious (e.g., supervisor, advisor, mentor), we elected to focus on the faculty-graduate student relationship as a mentoring relationship because of the importance of this relationship to graduate students' training and the assumption that this relationship involves mentorship to some extent, given the apprenticeship model characteristic of STEM graduate education.

High-quality mentorship is characterized by provision of career and psychosocial support to the mentee and the overall satisfaction, trust, effectiveness, and reciprocity of the mentoring relationship (Eby et al., 2013; Eby and Robertson, 2020). Such mentorship during graduate education is an essential element of graduate students' development, training, and success (NASEM, 2019). Multiple studies have shown the power of effective mentorship, demonstrating that mentoring is positively related to graduate students' persistence in academic research (McGee and Keller, 2007; Williams et al., 2016), scholarly productivity (Cronan-Hillix et al., 1986; Tenenbaum et al., 2001; Steiner et al., 2002, 2004; Paglis et al., 2006; Lunsford, 2012), research self-efficacy (Tenenbaum et al., 2001; Paglis et al., 2006), rate of degree completion (Lunsford, 2012), and program satisfaction (Lunsford, 2012; McAllister et al., 2009). In fact, some scholars have argued that a graduate student's relationship with an advisor is the most important influence on the doctoral student experience (Lovitts, 2002; Barnes and Austin, 2009; Zhao et al., 2007; Sverdlik et al., 2018). This may be particularly true for graduate students in STEM fields, because their dissertation research is often directly related to the research agendas of their advisors (Golde, 1998, 2005; Welde and Laursen, 2008).

Despite its apparent importance, graduate mentorship in STEM is understudied compared with studies of mentoring in workplace settings (NASEM, 2019). Meta-analyses of mentoring in the workplace have found small to moderate effects of being mentored (Allen et al., 2004; Eby et al., 2008b, 2013; Eby and Robertson, 2020). Furthermore, these studies revealed substantial heterogeneity in the size of the effects of mentorship, suggesting that simply being in a mentoring relationship will not always lead to positive outcomes. Rather, these findings suggest that certain mentoring practices are more effective than others, that the quality of mentorship can vary, and that not all mentoring relationships are beneficial (Eby et al., 2000; Ragins et al., 2000). Scholars collectively refer to the dysfunctional elements of mentoring relationships or less than favorable interactions with mentors as "negative mentoring experiences" (Scandura, 1998; Eby et al., 2000; Simon and Eby, 2003; Limeri et al., 2019). However, the occurrence of a negative experience does not necessarily indicate that the entire mentoring relationship is negative or harmful. Instead, negative mentoring experiences can include problematic aspects of an otherwise positive or healthy relationship (Scandura, 1998; Simon and Eby, 2003). In fact, an extensive body of research on intense interpersonal relationships has shown that dysfunctional, unpleasant, or problematic events are likely to occur in any prolonged relationship (Kram, 1983; Duck, 1994).

Eby and colleagues' (2000) seminal work on the negative mentoring experiences of employees in the workplace revealed that more than $50 \%$ of mentees reported a negative mentoring experience with their workplace mentors, suggesting that negative mentoring may be a widespread issue. Negative mentoring experiences can range from mild, unintentional shortcomings, such as lack of mentor expertise or availability, to more severe and intentional behaviors, such as sabotage and harassment (Eby et al., 2000; Eby and Allen, 2002). These dysfunctional mentoring experiences can lead to a range of negative professional and personal outcomes, such as increased turnover intentions and deteriorating mental health (Eby and Allen, 2002). Furthermore, negative mentoring experiences can have a disproportionately strong effect on mentee performance, productivity, retention, and emotional state compared to high-quality mentoring experiences (Eby and Allen, 2002; Eby et al., 2010). In fact, negative mentoring in the workplace may be more detrimental than having no mentor at all (Eby and Allen, 2002; Eby et al., 2010). However, it remains unclear if these findings are transferable to STEM research settings and to graduate research in particular.

Johnson and Huwe (2002) hypothesized the potential dysfunctional mentoring experiences that graduate students could encounter with their research mentors in the form of a typology that included poor relationship match, mentor incompetence, neglect or abandonment, hostile or resentful behaviors, exploitation, coercion, and sexual attraction and exploitation. However, this framework has not been empirically tested. The handful of studies exploring less-positive mentoring experiences of graduate students are limited to the field of psychology (Goodyear et al., 1992; Kalbfleisch, 1997; Clark et al., 2000). A recent report indicated that there are no empirical conceptualizations of the construct of negative mentoring in STEM 


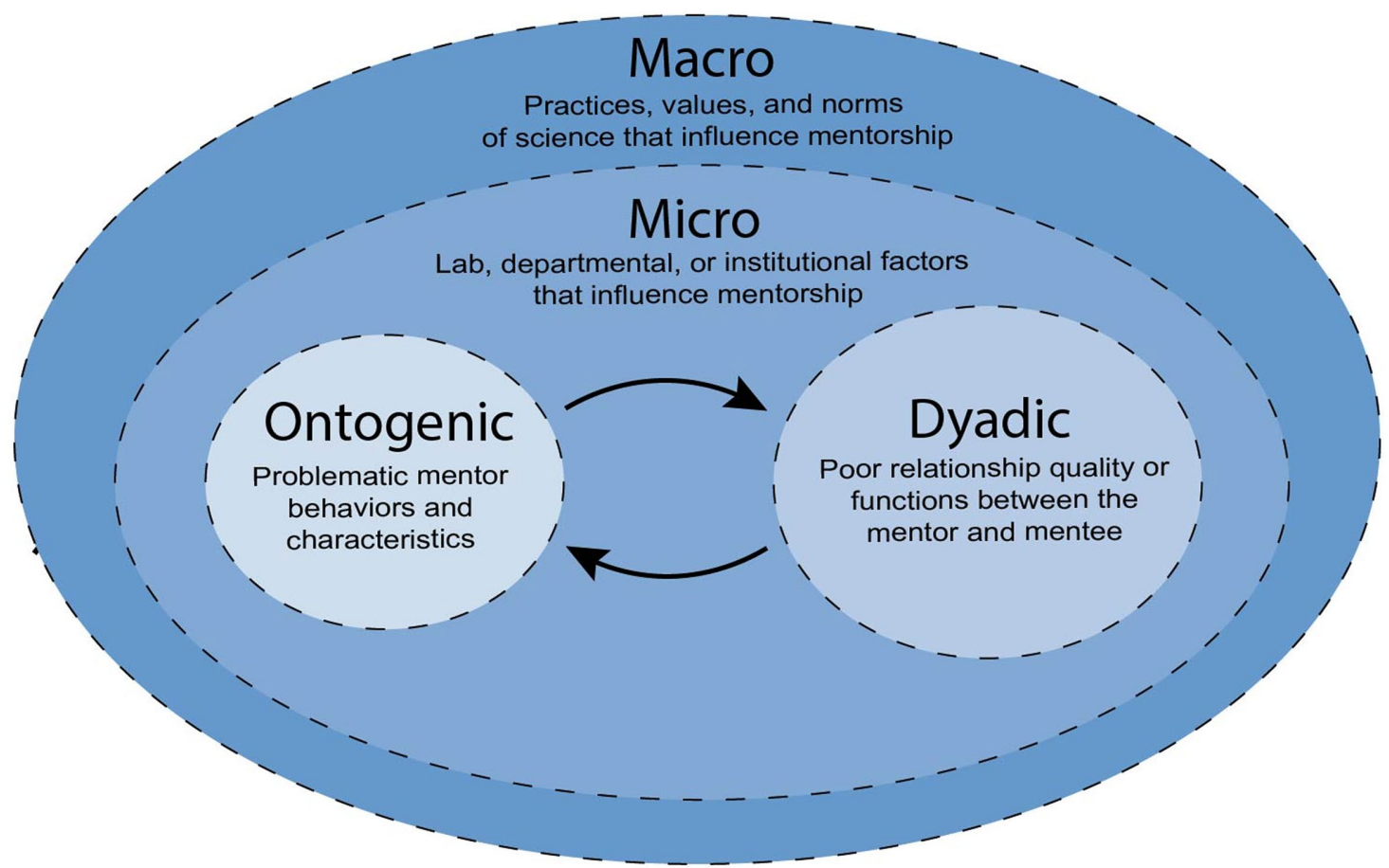

FIGURE 1. Ecological systems conceptual model of variables influencing the negative mentoring experiences of life science doctoral students. We used ecological systems theory to interpret our results and gain insight into how various individual, relational, and environmental variables influence graduate students' negative mentoring experiences. We found evidence that doctoral students' negative mentoring experiences are not only shaped by problematic mentor behaviors and characteristics (ontogenic) and poor relationship quality and functions (dyadic), but also by research group, department, and institutional factors (micro) as well as the culture of science and academic research (macro). Doctoral students perceived that factors at the micro and macro levels had dynamic, reciprocal effects at the dyadic and ontogenic levels.

graduate education (NASEM, 2019). The paucity of knowledge on this subject warrants attention, given graduate students' dependence on their advisors for support and the significant role that advisors play during graduate students' education (Zhao et al., 2007; Maher et al., 2017; Sverdlik et al., 2018).

In the present study, we conducted an exploratory investigation to define and characterize the negative mentoring that graduate students experience in their research. We conducted semistructured interviews with a sample of life science doctoral students in the U.S. $(n=40)$ who represented diverse institutions, sociodemographics, and program time points, and who indicated that they had negative experiences with their research mentors. Participants not only reported issues specific to their mentors and the mentoring relationship, but also spoke unprompted and candidly about research group, departmental, and institutional issues, as well as issues they attributed to the nature of academic science research that they perceived were affecting the mentoring they experienced. To capture these experiences, we made the post hoc decision to analyze and interpret our results using ecological systems theory (Bronfenbrenner, 1977; Chandler et al., 2011). Ecological systems theory allows for the investigation of the fundamental behaviors and processes of individuals and their relational aspects, as well as how these practices and norms are shaped by organizational and disciplinary cultures. By using this analytical framework, we gained insight into the contextual factors, including departmental-, institutional-, and discipline-level issues, that graduate students perceived as shaping and constraining their mentoring experiences (Chandler et al., 2011). We report the results of these analyses at each level of the graduate life science research mentoring ecosystem, ranging from interpersonal differences and poor relationship quality, to issues at the research group, departmental, organizational, and discipline levels, all of which doctoral students perceived as impacting their personal and professional development (Figure 1).

\section{METHODS}

This study was reviewed and determined to be exempt by the University of Georgia Institutional Review Board (STUDY00006750).

\section{Participants}

We used a purposeful sampling strategy (Merriam, 1998) to recruit a diverse group of participants with respect to social identity (e.g., gender, race/ethnicity) and institution (e.g., private/ public, location). We contacted potential participants by emailing Listservs of life science professional society graduate student groups, asking administrators and graduate coordinators at U.S. research universities to distribute study invitations to doctoral students, and emailing doctoral students directly at the email addresses publicly available on department websites from U.S. research institutions. Participants were also asked to share the study information with peers whom they believed met the study criteria (i.e., snowball sampling). Because we distributed emails 
to lists and departmental directories, we are unable to accurately estimate response rates.

We chose to focus on doctoral students in the life sciences, because the life sciences represent the largest and most demographically diverse subfield within STEM in the U.S. (National Science Foundation [NSF], National Center for Science and Engineering Statistics, 2019). We also expect the mentoring norms and practices, as well as the nature of graduate education, to differ across STEM disciplines; we sought to account for these differences to some extent by limiting our sample to the domain of life sciences. It is worth noting, however, that the life sciences span a wide range of research contexts and approaches (e.g., bench, fieldwork, computational). Thus, to some extent, the life sciences may serve as a microcosm of the range of mentorship that STEM graduate students experience. We minimized recruitment from our own institution, given the proximity of participants to our research group and the sensitivity of the subject matter. Not surprisingly, the majority of doctoral students were reluctant to participate without being granted complete confidentiality due to the sensitive nature of the topic and fear of repercussions. Some of our participants reported they only participated in our study because they would be graduating before the dissemination of the study results, which they believed would minimize potential repercussions.

Participants were emailed the study information and a link to an online screening survey (see Supplemental Material) using the secure survey service Qualtrics, following a screening procedure similar to prior research on the negative mentoring experiences of undergraduate life science researchers (Limeri et al., 2019). In the screening survey, participants self-reported their eligibility, specifically that they: 1) were working or had worked as a graduate researcher for at least one academic year; 2 ) were pursuing or had earned a $\mathrm{PhD}$ in a life science discipline within the past year; and 3) had at least one experience that was perceived as negative with their research mentor, therefore having a direct experience with the phenomenon under study (Morse et al., 2002). Participants were asked to rate the quality of their mentoring relationships with their graduate advisors and the quality of their graduate education experiences on two, seven-point Likert-scale items ranging from -3 to +3 and to explain the rationale for their ratings. Finally, participants were asked to report demographic information (e.g., degree status, years of $\mathrm{PhD}$ completed, gender, race, and ethnicity).

We received 101 survey responses with varying degrees of completion. We strategically selected for interviews a sub-sample of these individuals who rated their relationship quality with their graduate advisors as negative or less than ideal $(+1$ to -3 ) and who represented a range of personal characteristics, program time points, and institutional affiliations and thus could report on a range of dysfunctional mentoring experiences (Patton, 1990). We also used the short-answer section as confirmation that we were inviting doctoral students to participate who had indeed experienced a range of negative mentorship. We contacted 50 individuals and ultimately interviewed 40 individuals (10 did not respond to the interview invitation), representing 22 U.S. institutions, including public and private institutions that were classified as high or higher research activity (Carnegie Classification of Institutions of Higher Education, accessed December 2019; see Table 1). We opted to stop additional data collection after interviewing these 40 individuals, because we had reached saturation, meaning that participants began reporting ideas that had already been described by other participants (Guest et al., 2006). We elected not to ask participants to provide any information about their mentors (e.g., career stage, participation in mentoring professional development), because exploring the influence of these factors would require a different study design and methods, although some of this information was revealed organically during the interviews.

\section{Data Collection}

We collected data using semistructured interviews over phone or videoconference. Each interview lasted 40-60 minutes and was audio-recorded. T.T.T. (a life science doctoral student) conducted all of the interviews to ensure consistency and because we believed that participants would be more forthcoming about their experiences with a peer. We designed the interview questions to gain an in-depth understanding of any negative or problematic aspects of the mentoring that doctoral students experienced during their research. Specifically, our questions probed into doctoral students' perceptions of their mentors' behaviors and traits and the quality of their relationships with their mentors, as well as any problematic events, situations, or negative elements of their mentoring experiences (see Supplemental Material). We did not ask participants about how their research groups, departments, institutions, or disciplinary culture contributed to their negative mentoring experiences, but participants described these issues unprompted. When participants commented on these elements, we asked spontaneous follow-up questions to understand how these components shaped their mentoring experiences. Interview recordings were transcribed verbatim by Rev.com and checked by the researchers for accuracy. All identifying information that participants described in their interviews (e.g., names of individuals and institutions, research techniques, model organisms) were removed and replaced with pseudonyms to protect participant confidentiality. Participants were offered a \$25 Amazon gift card as compensation for participating in an interview.

\section{Data Analysis}

We conducted qualitative content analysis to define and characterize negative mentoring experiences in life science doctoral education. Because participants brought up contextual factors unprompted, we saw a need for additional theoretical framing to fully understand these mentoring experiences. Therefore, we used ecological systems theory to understand how multilevel influences shape negative mentoring outcomes. Ecological systems theory posits that phenomena are shaped by multiple environments (i.e., systems) that interact with and influence one another (Bronfenbrenner, 1977). We used this theory in our analysis to understand how negative mentoring experiences are shaped and effected by systems occurring at four distinct levels_-individual mentor issues (ontogenic system), relationship issues (dyadic system), local environmental influences (micro system), and discipline-level influences (macro system; Figure 1; Chandler et al., 2011).

We began our analysis by importing the interview transcripts into MaxQDA (Verbi Software, 2019) for open coding to identify segments of the text (i.e., quotes) that described a distinct negative mentoring experience (Saldana, 2015). T.T.T. carefully 
TABLE 1. Study sample demographics $(n=40)$

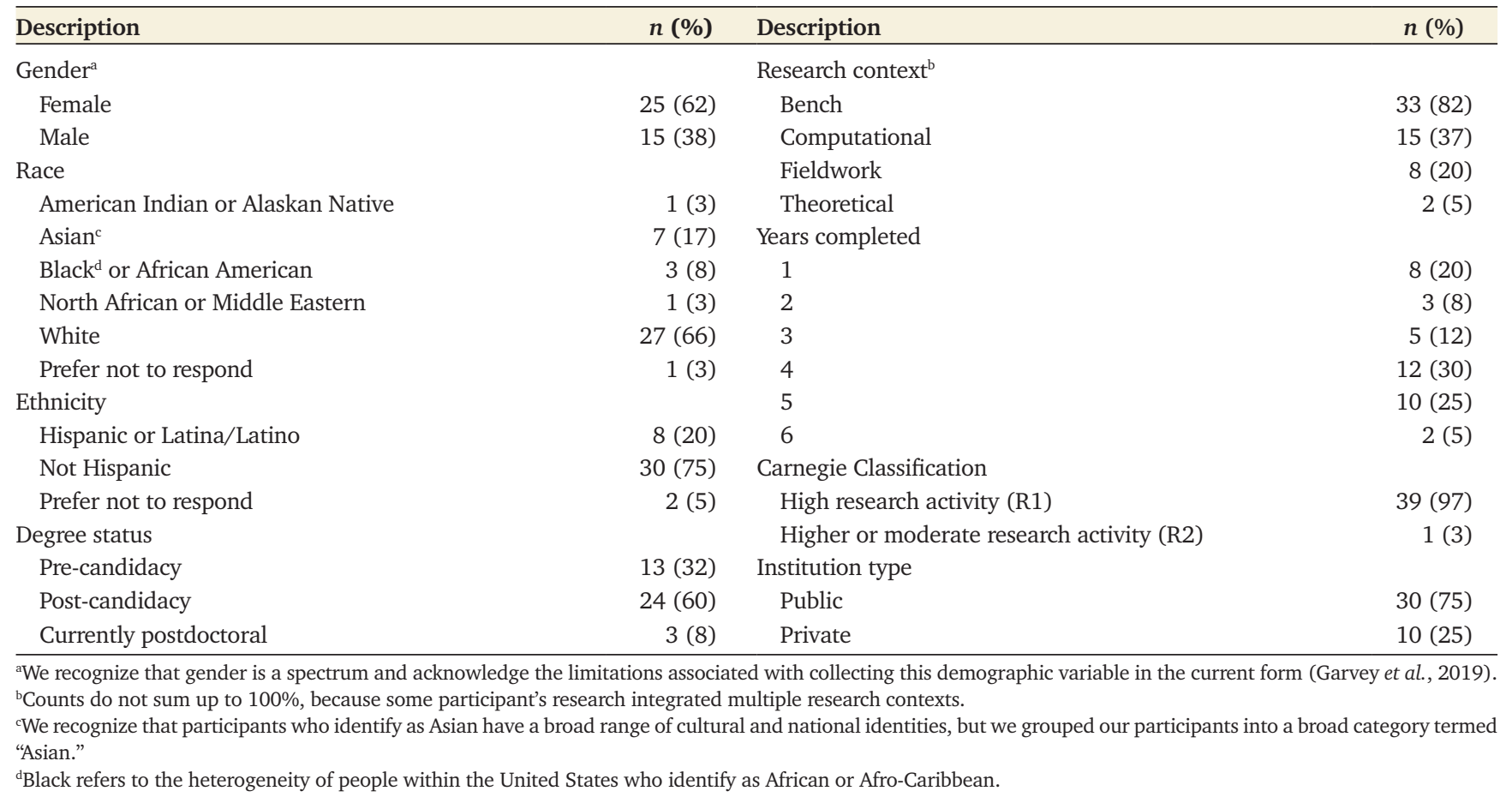

read and identified distinct negative mentoring experiences, which were then categorized into one of the four systems outlined in ecological systems theory. T.T.T. and E.L.D. independently indexed a subset of the quotes from each of the four levels individually using an a priori set of codes originating from earlier studies examining the negative mentoring experiences of employees (Scandura, 1998; Eby et al., 2000) and undergraduate researchers (Limeri et al., 2019) to generate a preliminary codebook. We also incorporated themes from literature describing supervisory issues in the workplace (Cortina et al., 2001; Schyns and Schilling, 2013; Tepper et al., 2017). We expected that the integration of these themes would help us interpret and make meaning of the data. Our codes consisted of short phrases or sections of the text that contained a specific example of a negative mentoring experience, in addition to a definition to describe the experience.

We then tested our preliminary codebook with the entire data set. At least two researchers (T.T.T., J.D.A., B.C.H.) reread each transcript in its entirety, looking for evidence of negative mentoring experiences, and coded the transcripts using our preliminary codebook in a very iterative process. We met after coding several interviews to discuss our codes until we reached consensus. When we came across a new phenomenon that was not represented in an existing code, we created a new code to capture this experience (Starks and Brown Trinidad, 2007). When we added, modified, or collapsed codes, we revisited our prior transcripts and looked for evidence of quotes that were aligned with the revised code (Saldana, 2015). Throughout this process, we further refined the definitions of the codes to ensure that our codes accurately captured the participant experiences. For experiences on which we could not reach consensus, we consulted with an additional author until consensus could be reached. We also used axial and pattern coding to identify and group together codes that represented similar themes in order to capture the common ways that doctoral students experienced negative mentoring (Strauss and Corbin, 1998; Saldana, 2015). For example, codes relating to problematic supervisory issues (e.g., abusive, micromanaging, hands-off) were all grouped into one theme termed "supervisory styles."

We took additional methodological steps to ensure that our analysis accurately captured contextual variables that were related to participants' negative mentoring experiences. We used process coding, which identifies actions or gerunds in the data in order to examine connections and processes between phenomena (Saldana, 2015). This approach allowed us to identify potential relationships between negative mentoring experiences across the system levels to determine how these phenomena related to themes in the ontogenic and dyadic systems. Specifically, we looked for instances of micro (local environmental influences) and macro (discipline-level influences) phenomena and attempted to trace these instances back to how doctoral students described them as influencing their mentors' attitudes, behaviors, or characteristics (ontogenic) or their relationships with their mentors (dyadic). We included the experiences that we could trace back to ontogenic or dyadic phenomena and excluded the experiences that did not have a clear connection to a mentor or mentoring per se. For example, we included experiences for which participants described how contextual variables shaped their mentors' behaviors and mentoring relationships (e.g., promotion and tenure). Some participants recalled poor experiences with graduate school (e.g., dysfunctional departments or institutions, systematic inequalities), but they did not specify whether or how these experiences related to their mentoring experiences, so these experiences were not included. After we completed our analysis, we organized the emergent themes into a conceptual model to explain 
the manifestations of negative mentoring experiences within the academic life science research ecosystem.

We took several steps to ensure the trustworthiness of our findings. First, we repeatedly compared quotes within and across codes and across systems to ensure that our thinking remained stable over time (Kolb, 2012). Second, all researchers were fully immersed in the data for an extended period of time and read the transcripts multiple times during the analysis, which allowed us to critically and thoroughly analyze and interpret the data. Two or more researchers coded all of the data to consensus, which reduces potential variability among coders and minimizes the likelihood of omitting critical components of this complex construct (Belur et al., 2018). We also sought out external feedback from experienced qualitative researchers, life science graduate faculty, and members of the University of Georgia Biology Education Research Group, who provided an outside perspective on our data and interpretations to help ensure the credibility and dependability of our findings (Lincoln and Guba, 1985; Hsieh and Shannon, 2005).

\section{Researcher Characteristics}

Our experiences and perspectives as researchers are also relevant for interpreting the results. T.T.T. (doctoral student), J.D.A. and B.C.H. (undergraduate students), and E.L.D. (faculty member) are researchers in life science departments at a public, high research activity doctoral university and have science training in the life sciences. We were all familiar with prior research on negative mentoring experiences in the workplace and undergraduate research settings. Our familiarity with this literature helped us identify and ascribe meaning to various types of negative mentoring experiences, while the open-coding process helped to ensure that our analysis included the experiences unique to doctoral students. We have all participated in mentored research experiences in the life sciences, and we (T.T.T. and E.L.D.) have prior experience studying mentoring relationships in academic and research settings. Our complementary positionalities as a research group helped us balance potential biases and strengthened our holistic interpretation of the data (Miles et al., 2014). Specifically, E.L.D. is the PI of a research group with 15+ years' experience mentoring graduate students and is the doctoral advisor of T.T.T. Additionally, J.D.A. and B.C.H. are undergraduate researchers who brought an "outsider" perspective to the graduate mentoring relationship.

\section{RESULTS}

Here we present the findings of our exploratory study to describe and characterize the negative mentoring experiences of life science doctoral students. Doctoral students in our sample attributed their negative mentoring experiences to multiple levels of the science research ecosystem: practices, values, and norms of science that influence mentorship (macro system); research group, departmental, or organizational factors that influence mentorship (micro system); relationship quality and functions between the mentor and mentee (dyadic system); and mentor behaviors and characteristics (ontogenic system). We present descriptive accounts of the ways doctoral students in our sample experienced negative mentoring, starting with the overarching themes at the macro level and concluding with the mentor-specific traits at the ontogenic level (summarized in Table 2). We also indicate the number of participants who reported experiences related to each theme to give some sense of the commonality of the theme in our sample. However, counts should not be interpreted as indicators of the prevalence of negative mentoring experiences in the national population of life science doctoral students, because our study design and methods were not intended to measure frequency.

\section{Macro System}

The macro system refers to the practices, values, and norms of academia and life science research that influence mentorship practices and shape negative mentoring experiences. Doctoral students described four macro-level phenomena that they perceived as influencing the mentorship they received: gatekeeping, lack of incentives for quality mentorship, power structures, and role tension (presented alphabetically).

Gatekeeping. Several participants $(n=5)$ described the culture of graduate education and of science in general as a gauntlet where only the "best" survive. Participants felt that the culture of academic science research supported the view of science and graduate training as extremely difficult and that poor mentorship was a necessary part of training that would ultimately help them succeed or "weed out" those who would not be successful. In this sense, negative mentoring experiences were promoted as a gatekeeper to deter individuals who did not have the necessary talent or disposition. Participants described the culture of academic training as one in which only those who were the strongest, smartest, and most passionate would survive and be able to pursue a career in science. The people who left science because of negative mentoring experiences were perceived as doing so because they lacked the characteristics or talent to prosper as a scientist, as Makayla recalled:

I did an internship at a large funding organization ... I was talking with my supervisor one time ... and they said "Well, we don't care about the people who give up because they are badly mentored. We care about the people that are so great that they will become great scientists no matter what people do to them"... That's the attitude that people have in science. The fact that it's not supposed to be a profession or a job, but that it's supposed to be a passion ... Some sort of like tortured artist thing whereby you're so passionate about your art that they can't make you not do it ... And that is such a toxic attitude ... but people see being deterred by bad mentoring as lack of commitment to the art.

Lack of Incentives for Quality Mentorship. Some doctoral students $(n=6)$ in our sample described cultural beliefs, values, and norms within academic research that undermined the formation of high-quality mentoring relationships. In most cases, participants explained that their mentors were focused on advancing their own careers (e.g., achieving promotion and tenure) and that providing quality or effective mentorship would not help them achieve these goals. Specifically, participants explained that only research productivity (i.e., grant funding, publications) were weighed in how their mentors were evaluated and that there were no incentives, rewards, or expectations to provide quality mentorship. For instance, Kamala reasoned that the promotion and tenure process played a key role in shaping her marginal mentoring experience: 
TABLE 2. This table presents the main forms of negative mentoring experienced within each level of the doctoral research mentoring ecosystem, including their conceptual definitions (left column) and the operational manifestations (right column).

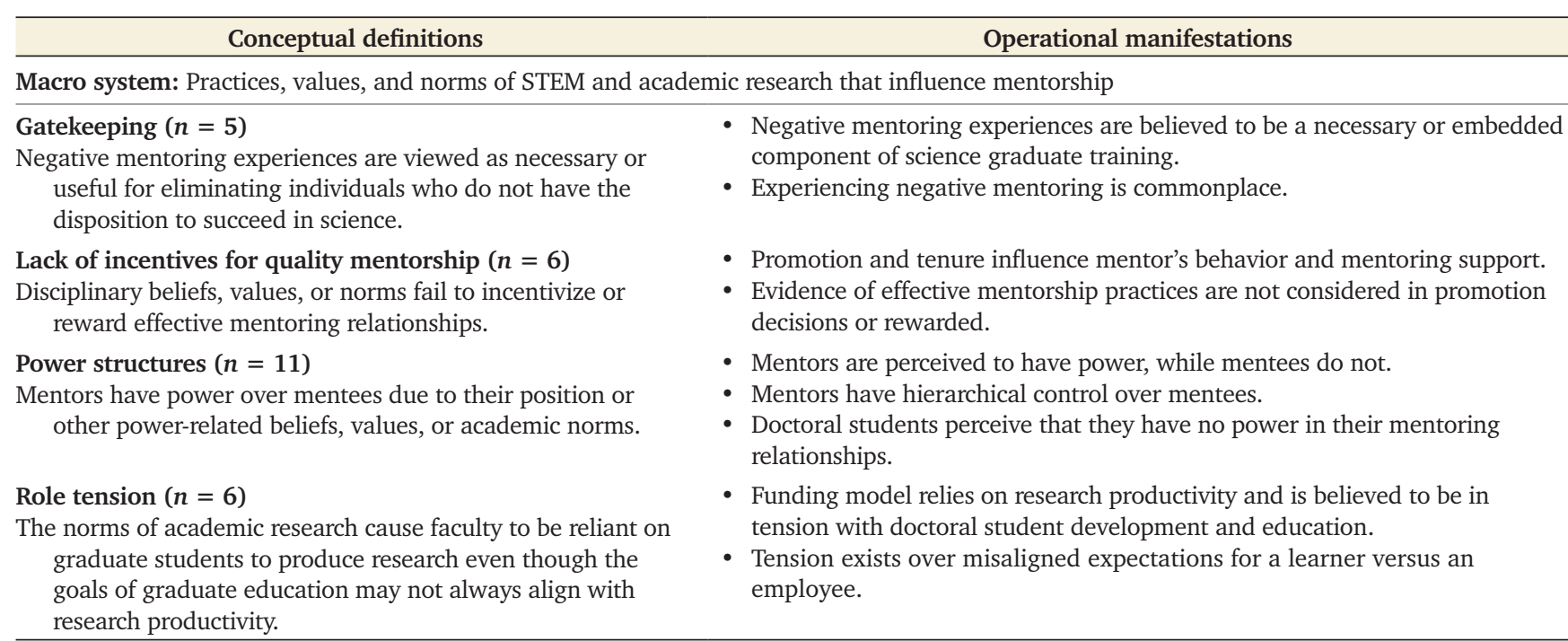

Micro system: Lab, departmental, or institutional factors in the local environment that contribute to and influence mentorship

Collegial protections $(n=8)$
Mentee perceives that mentors in their department are safe from repercussions because of their seniority, department/ program needs, or academic freedom.

\section{Insufficient structure $(n=18)$}

Mentee believes that there is a lack of policies, procedures, or supports to assist them when experiencing dysfunction in their mentoring relationship.

Social undermining $(n=23)$

Mentee believes that the mentor engages in actions that damage and undermine the mentee's ability to establish and maintain healthy working relationships in their local environment.
- Untenured mentors appear reluctant to stand up against senior, tenured faculty.

- Programs or departments continue to allow mentors to mentor even when they are known to engage in detrimental mentoring behaviors.

- Faculty justify or support mentors' actions, even if they are viewed as being harmful.

- Faculty have academic freedom that allows them to mentor as they see fit.

- Departmental or institutional leaders do not provide support or intervene to provide mentee with mentoring support.

- Policies or plans to mitigate negative mentoring experiences are absent.

- Departmental or institutional culture is perceived as not being conducive for fostering healthy mentoring relationships.

- Mentor gossips, spreads rumors

- Mentor belittles or gives contradictory advice during dissertation committee meetings

- Mentor talks down to mentee in front of others

- Mentor engages in actions that damage mentee's work-related success

- Mentor fosters a poor or hostile working environment

- Spousal presence negatively influences research group

Dyadic system: Poor relationship functions or forms of support between the mentor and the mentee

\section{Interpersonal mismatch $(n=19)$ \\ Mentee and mentor and have dissimilar values, personalities, workstyles, or communication preferences.}

Limited career support $(n=38)$

Mentee reports not receiving sponsorship, coaching, networking and exposure, or advice related to their career goals from the mentor.

Limited psychosocial support $(n=28)$

Mentee feels that they did not receive counseling, affirmation, emotional support, acceptance, or confirmation from the mentor.

Poor relationship quality $(n=19)$

Mentee has poor feelings about the mentoring quality or is generally unsatisfied with the mentoring relationship.
- Mismatched personalities

- Dissimilar career goals and outcomes

- Dissimilar research interests

- Different life priorities or values

- Lack of engagement or interest in mentee's research or career development

- Insufficient safety training

- Lack of technical guidance

- Limited or no feedback or advice on networking, career options, publishing, grant writing

- Insufficient provision of networking or development opportunities

- Passing judgment on mentee's career achievements or goals

- Insufficient encouragement or validation

- Lack of investment in mentoring relationship

- Little emotional connectivity or disclosure in the relationship

- Mentee dissatisfied with mentor

- Mentee and mentor generally dislike or distrust each other.

- Mentor does not engage in social-/relationship-building activities with mentee. 
TABLE 2. Continued

\begin{tabular}{|c|c|}
\hline Conceptual definitions & Operational manifestations \\
\hline \multicolumn{2}{|l|}{ Ontogenic system: Problematic mentor behaviors and characteristics } \\
\hline $\begin{array}{l}\text { Deceit }(n=12) \\
\text { Mentor misrepresents information or witholds it from the } \\
\text { mentee. }\end{array}$ & $\begin{array}{l}\text { - Lies to mentees about how their ideas or research will be used } \\
\text { - Tells the mentee one thing and then does something different } \\
\text { - Keeps mentee "out of the loop" on important issues }\end{array}$ \\
\hline $\begin{array}{l}\text { Inaccessibility }(n=38) \\
\text { Mentor has too many professional obligations or events in their } \\
\text { personal life that excessively limit the amount of time the } \\
\text { mentor can commit to the mentee. }\end{array}$ & $\begin{array}{l}\text { - Absent due to excessive traveling for conferences, fieldwork, or other } \\
\text { - } \text { Abmitments } \\
\text { - Does not spend time with mentee in favor of spending time writing grants, } \\
\text { - carrying out service responsibilities, or working on other research projects } \\
\text { - Mental and/or physical health issues of the mentor or mentor's family } \\
\text { - Experiences marital troubles/divorce }\end{array}$ \\
\hline $\begin{array}{l}\text { Limited expertise }(n=23) \\
\text { Mentor appears to not have the knowledge, skills, or abilities to } \\
\text { effectively guide the mentee. }\end{array}$ & $\begin{array}{l}\text { - Not current on ideas, theories, methods, or findings related to mentee's } \\
\text { research } \\
\text { - Unable to give technical advice or guidance } \\
\text { - Unable to effectively guide research or effectively supervise or mentor } \\
\text { others }\end{array}$ \\
\hline $\begin{array}{l}\text { Limited interpersonal abilities }(n=34) \\
\text { Mentor has persisting attitudes, behaviors, or personality traits } \\
\text { that limit their ability to communicate or interact with the } \\
\text { mentee effectively. }\end{array}$ & $\begin{array}{l}\text { - Has a bad attitude, is rude, condescending, dismissive, defensive, } \\
\text { narcissistic, conceited } \\
\text { - Has oscillating mood or personality changes, is passive-aggressive, or } \\
\text { behaves impulsively } \\
\text { - Discusses romantic interests or intimate details, makes inappropriate jokes } \\
\text { or comments, overshares personal information } \\
\text { - Gives unsolicited personal advice }\end{array}$ \\
\hline Supervisory styles $(n=34)$ & - Takes credit \\
\hline $\begin{array}{l}\text { Mentors approach to managing and directing does not match } \\
\text { the mentee's needs. }\end{array}$ & $\begin{array}{l}\text { - Punishes, intimidates, threatens, coerces, calls names, swears, yells } \\
\text { - Encourages competition among lab members } \\
\text { - Is detached from mentee's day-to-day needs } \\
\text { - Has a philosophy of little to no collaboration on research, of minimal } \\
\text { communication or feedback } \\
\text { - Meticulously oversees or is over-involved in research tasks } \\
\text { - Attempts to control how mentee conducts research, allows mentee little } \\
\text { autonomy or ability to make decisions about research }\end{array}$ \\
\hline Unequal treatment $(n=14)$ & - Discrimination \\
\hline $\begin{array}{l}\text { Mentor treats mentee differently based on personal characteris- } \\
\text { tics or mentor preferences. }\end{array}$ & - Favoritism \\
\hline
\end{tabular}
tics or mentor preferences.

My mentor doesn't have tenure yet, so a lot of the things that she's done I felt have been because she's presumably under a lot of pressure to get tenure ... She made me feel like my research didn't deserve as much attention as some others' in the lab ... I wanted to apply to give a talk at a conference ... and at this point I'm a sixth-year graduate student and I presented my first poster two months ago ... I tried to talk to her about it because I would really like to present and get feedback on my work. She said "Well, you're welcome to try to get an abstract but I want you to apply to conferences where no one will know me." Because outside feedback from people in her field, that aren't at the same university is an important part of her tenure package and how she's evaluated ... She's trying to establish herself in the field ... and market the lab in a very specific way, and my sense is that my project didn't fit into that.

Power Structures. About a quarter of the participants $(n=$ 11) described how the power differentials and hierarchy between graduate students and PIs were pervasive elements of academic culture that contributed to their negative mento- ring experiences. PIs were perceived as having the freedom to function as they pleased and were able to exert power over their mentees without any checks and balances or accountability for their actions. For example, Su described how "the bad professors can do whatever they want and have to do something super, super bad in order to get punished." Other participants felt their mentors were "untouchable," even as assistant professors without tenure, although full and associate professors were believed to be even more powerful. For example, some mentors blatantly told their mentees that they were in the position of power, which allowed them to coerce or threaten their mentees (e.g., withholding a letter of recommendation). Participants felt that the power differential allowed dysfunctional mentor behaviors (ontogenic) and poor mentoring relationships (dyadic) to develop and persist. Because of mentors' power and control, participants felt unable to defy their mentors or address issues with them. For example, Jada experienced mentoring issues at the ontogenic and dyadic levels that she attributed to her reliance on her mentor for professional endorsement: 
This is not just a teacher or a professor that I'm taking a course with, this is my mentor, my PI. Any letters of recommendation that I really need would come from him because he's known me ... for an extended period of time. But I choose not to dwell on [my issues with him] or show negative feelings towards him, because I know that he still has to sign off on my degree. He still has to write a letter. I may need his connections ... I need his approval at the end of the day.

Participants also described how the norms of science, especially the enactment of these norms in policy and practice, contributed to and enforced the power differential between doctoral students and faculty. For example, participants explained how graduate program policies and procedures ensured PIs held power because PIs had to sign off or approve mentees' research in order for mentees to graduate. Other participants explained that it was a norm in the discipline for their PIs to serve as authors on their research publications, regardless of their contribution to the project, which reinforced PIs' power over doctoral students. Kara recalled her experience writing a paper and then submitting it to a journal in her PI's name to increase the likelihood of it being favorably reviewed because of her PI's reputation and connections (i.e., power), as opposed to the quality of the work.

We submitted the proposal for the editorial review board to consider and you can only submit it in one person's name. We know someone on the review board and they said we should definitely submit it in your advisor's name because they won't accept something by an unknown grad student. Just put down your advisor's name and they'll definitely look at it and consider it. It was sort of funny ... I wrote the entire outline, the intro letter, and the entire application. She didn't really do anything with it, but then we submitted it in just her name.

Role Tension. Several doctoral students $(n=6)$ reported that there appeared to be a tension in academic research between graduate education as a developmental experience and graduate research as a job. Specifically, doctoral students felt that they were simultaneously playing two competing roles: a learner and an employee. Many doctoral students were funded from their PIs' research grants, which set up the implicit expectation that they were employees. Participants described how their mentors treated them like employees whose sole responsibility was to produce research results and thus the mentors actions tended to be supervisory rather than concerned with mentees' development. Some participants indicated that they were expected to produce data constantly and that there was little room for career exploration or skill and interest development that did not directly relate to their research. For example, mentors were known to be reluctant about supporting mentees' pursuits or interests outside of academic research (e.g., internships, professional development courses), because this meant they were not working on the projects that their mentors viewed as valuable or productive. This disconnect about the purpose of graduate education allowed for tension to form regarding the type of relationship and support the mentees desired and what their mentors were able to provide. Ash explained:
I definitely feel like a cog in a machine ... me being viewed as like a disposable or interchangeable asset rather than a developing scientist or a human myself. Like I am an employee working for a salary, just churning out results, rather than a student or mentee that needs mentorship and might go onto bigger things one day.

Collectively, these macro-system results indicate that graduate students in our sample attributed at least some of the negative mentoring they experienced to aspects of academic research and the nature of graduate education. These participants acknowledged that at least some of their poor experiences with mentors were attributed to the larger system rather than the ill intent of individual mentors.

\section{Micro System}

The micro system refers to factors in the local environment, including the research group, department, and institution, that contribute to or otherwise influence graduate students' negative mentoring experiences. Participants described three microlevel phenomena: collegial protections, insufficient structure, and social undermining.

Collegial Protections. A fifth of our participants $(n=8)$ described how faculty in their graduate programs were protected when doctoral students expressed concern over their mentoring relationships. The protections occurred for a variety of reasons that included academic freedom, seniority, and program or departmental needs. Doctoral students perceived that these protections allowed mentoring problems to go unchecked or unresolved because many faculty were hesitant to address or confront their colleagues. For example, doctoral students described how early-career, untenured faculty appeared unwilling to intervene to defend graduate students who experienced negative mentoring behaviors from senior, tenured faculty. Doctoral students also perceived that faculty mentors who were known to be successful with grant funding or private donations were also allowed to mentor as they pleased. Some participants noted that their mentors were "very likeable" in their department and had received awards or formal recognition for their research, teaching, or mentoring, making it difficult for doctoral students to gain credibility when they claimed they were experiencing dysfunction in the mentoring relationship. Other doctoral students explained how faculty took a laissez-faire attitude toward colleagues' mentoring behaviors because interfering ran counter to the tenet of academic freedom. The prevailing belief in these local environments was that faculty were free to function as they pleased because of their position or status in the university, as Brock explains:

Everyone knew how poor my [mentoring relationship] was. People would stop me in the hallway and tell me like, "I've heard how poorly things are going with the [mentor]." And I'm like, "yeah it sucks." And they'd be like, "I'm so sorry," and move on ... All you did is make yourself feel better about making me understand that you know, but aren't going to do anything ... Step up, you are tenured. Tell that person to stop behaving this way ... I completely understand, for someone that's tenure track, I also would not put my career on the line. But if you're tenured, I don't understand why people wouldn't just call it out and say, "That person is behaving poorly and abusing people. What's the risk?" 
Insufficient Structure. Nearly half of the participants in our study $(n=18)$ expressed concern about a lack of policies or procedures aimed at providing structure or addressing issues that arose in mentoring relationships. Some of these students were in situations that were particularly unstructured, such as their mentors being on sabbatical or on personal leave for an extended period. Students in these situations noted that they did not receive any support or resources from the department or university to take the place of their inaccessible mentors. Other students focused on the lack of structure for reporting mentoring issues. Several participants sought out help from their graduate coordinators or departmental and institutional leadership. Of these participants, some reported that their attempts were dismissed or that they were actively discouraged from reporting mentoring issues. Others reported not seeking support because they perceived that these attempts would be disregarded or not taken seriously or that the individuals in these positions were inaccessible or unwilling to advocate on their behalf. Yet other participants described a competitive or hostile departmental culture that made them hesitant to show any signs of shortcomings, either of their own or their mentors. They were concerned that bringing attention to mentoring issues would be a sign of weakness for themselves or their mentors. Collectively, these students believed that there should have been program-level supports in place to assist them when they were experiencing mentoring issues, as Laurel highlights:

At my university if two faculty members have conflict, then they go to HR [human resources]. If two graduate students have a conflict, I think they go to the chair of the department. But if a graduate student and a faculty member have a conflict, there is no course of action or procedure ... So there's really nowhere to go if you are having issues.

A number of doctoral students felt that dissertation committees were a natural structure to buffer against limited support from their mentors. However, several students described how their attempts to receive support from their committee members were unsuccessful. Participants recalled that it was common for their committee members to have constraints on their time, resources, and expertise that prevented them from providing effective mentoring support. For example, Olivia described how she relied on her committee members, because her mentor was inaccessible, but struggled to receive adequate support:

I've been trying to reach out more and rely on [committee members] for resources. My committee hasn't really been too great, but they also aren't being difficult ... I feel like I'm not getting enough guidance from them ... The one that I thought would be the bioinformatics person, I found out that they are not a bioinformatics person. He hasn't been helpful. Another is just very absent, he's like, "get it done and get out of here." The third, is really nice and I like her, but they are the furthest removed from my research ... I feel like I'm not getting any real guidance on the direction of my research.

Social Undermining. More than half of the doctoral students in our sample $(n=23)$ described instances when mentors acted in ways that undermined their standing in their research groups, departments, and institutions (Duffy et al., 2002). Although these behaviors could fit within the ontogenic system, we categorized these experiences as part of the micro system, because participants described these experiences as having micro system-level effects, such as harming their relationships and reputation with others in their local environments. Doctoral students described instances when mentors gossiped or spread rumors about them, created divisiveness between the mentee and others, or made insidious or belittling comments about them in front of dissertation committee members, research group members, or other influential people in the students' immediate environments. Doctoral students felt these damaging remarks seemed out of place or inappropriate, especially in the presence of others. They perceived these actions as harming their reputations and research-related success, as Isaac explained:

We would have a group class that she would teach. In the middle of lecture she'd start critiquing me in a way that was nothing to do with the lecture or anything ... These sort of small little snippets in front of other students that I feel are really not helpful ... plus I don't understand why a professor would demean a student in front of other students. I understand it being critique in a one-on-one meeting setting, but to critique someone actively and verbally in front of other students I was uncomfortable with.

Participants also described how their mentors' interactions with other research group members promoted a working environment that was pernicious, aggressive, or otherwise not conducive to professional growth and productivity. These instances made it challenging for mentees to seek support from lab mates and strained their relationships with their mentors, especially if the mentor avoided or was unable to effectively address confrontations or disputes that occurred among lab members. Some doctoral students indicated that they were in research groups where the mentor's spouse was an employee in the group, and they described how this could contribute to negative mentoring experiences. These situations typically involved the student confiding in the spouse, who then reported the details of the conversation to the mentor. In other cases, a spouse's presence in the lab was perceived as a "spy" who then reported lab goings-on to the mentor. Doctoral students reported that these experiences led to a sense of discomfort and mistrust within the research group that compromised the quality of the work environment. Maria recalled how her mentor's spouse made it difficult for her to form working relationships with others or to solicit support from her mentor:

It was always him and his wife, they always had to be together in everything for some reason ... Our lab schedule was just so strict and we couldn't take a day off ... If we were late or took a day off, his wife would come yelling at us in front of everyone in the lab and it was just so scary ... the lifestyle of lab ... we just didn't have any liberty at all. [The spouse] was always on top of us and [my mentor] always took her side. He never took any perspective other than hers.

Considered together, these micro-system results indicate that local environmental factors either created situations where negative mentoring could be experienced or failed to protect doctoral students when negative experiences occurred. 


\section{Dyadic System}

The dyadic system is represented by the mentoring relationship, which encompasses its quality (e.g., level of trust, reciprocity, connectedness in the relationship) and functions (e.g., the level and forms of support the mentor offers the mentee). Experiences within the dyadic system were specific to individual mentee-mentor relationships and could vary from one mentee to another, in contrast to the ontogenic system, which was attributable to the mentor and affected all mentees. Doctoral students reported four forms of dyadic-level negative mentoring: interpersonal mismatch, limited career support, limited psychosocial support, and poor relationship quality.

Interpersonal Mismatch. Nearly half of the doctoral students in our sample $(n=19)$ noted that they did not match with their mentors in terms of personality, work style, communication preferences, or values. Mentees perceived that, because they did not match well with their mentors, they missed many of the outcomes associated with successful mentoring relationships. Some students noted general mismatches between themselves and their mentors. For example, Addison explained:

He would give, I suppose, "suggestions" and he wanted the students to guide the project ultimately, but I wanted a bit more of like, "Let's talk through these things together and then have an agreement about whatever I'm going to do and then I'll go do it." He was more of an ideas person and he was not a pragmatist, where I was always much more realistic.

Other participants commented on specific mismatches in terms of career goals that resulted in lower-quality relationships with their mentors. Adrianna explained how she and her mentor had different viewpoints and values on the goals of graduate school:

It got to a point where she was having a really hard time understanding why I cared for other things that weren't related to academia. She's like, "I think it's great that people out there in the world are doing things to make the world a better place." But she also just had a hard time understanding why I cared, when [she thought] my priority, and not only my priority, but the main thing in my life should only be grad school. That was very hard for me, because that's something very core of who I am ... improving the community.

Limited Career Support. Almost all of the graduate students in our sample $(n=38)$ expressed concerns that they did not receive sufficient career advice or scientific guidance from their mentors. Several graduate students described instances when their mentors prevented or discouraged them from presenting their research at or attending conferences. For example, Aaron described how his mentor did not allow graduate students with incomplete work to attend conferences: “[My mentor] doesn't allow his students to go to conferences unless their project is finished, because he has been scooped before and is fearful of that happening again."

Other participants described situations in which their mentors did not provide them with guidance or feedback with writing proposals, job applications, or manuscripts. Evan described his experience of attempting to secure funding for his research with little to no help from his mentor:
I wasn't funded when I came to the lab ... I am constantly applying for grants. I know that is your job as a grad student, but at some point, you're sort of expected to have a PI write for some money ... I just got an email from him and it says "Hi Evan. I just ran across this page of various grants. Cheers, Mentor." That's it. It's a link. A link to a website with 20 different hyperlinks. So, it's like yes, I know how to use Google ... Can you say the ones that you've applied to in the past that have been successful? Or that your colleagues applied to? I mean, I guess I need to take some responsibility. I'm a smart dude or I wouldn't be in grad school, but it's just overwhelming. I'm supposed to be teaching, taking classes, and I'm swamped with research and it's just like do all that while finding your [own] funding.

In other instances, participants wished that their mentors had advocated on their behalf in committee meetings or assisted them with networking at conferences. Addison described her experience of writing her dissertation and trying to defend her thesis while her mentor was not engaged:

I had met my end of the bargain and got [my mentor] the dissertation. He read the first two chapters of my dissertation and gave me edits, and skimmed the remaining three. Two of which were ones with data we had never really talked over ... so the lack of comments was especially not helpful ... He also wasn't advocating for me on behalf of my committee, he wasn't making time, he wasn't guiding any of the process. He would write, at least in two emails, "Just do whatever you need to do to make them like your dissertation. Just make it work." I would get some edits back from the committee and want to talk them over with him, and he would say "Just do it." I would and he would come back with, "Oh well now I need to edit this. I want more say in this." I was like, look, you can't give me full responsibility in doing it the way it needs to be done and then try to take it back and put your hands back in. Either you are in this and helping me or you let me do whatever I need to do to finish and you just sign it off.

Limited Psychosocial Support. The majority of doctoral students in our sample $(n=28)$ also expressed concerns about not receiving validation or appreciation from their mentors. Mentees wished that they had receive more verbal encouragement, counseling, or emotional support, particularly during challenging or stressful events in graduate school. For example, Thea commented on how her mentor's lack of encouragement undermined her development:

I wanted a lot more attention than he was giving me. I think a lot of that was because I was really insecure about research ... I just wanted someone to tell me that I was doing a good job or that I was in the right direction. I don't think I heard a "good job" from my mentor until I defended my dissertation.

Other doctoral students described instances when their mentors made comments that undermined their confidence. For instance, Rosalie described how her mentor frequently made comments that made her feel invalidated and unappreciated, explaining that "by the end ... I definitely wasn't happy, which I think is pretty normal ... I just didn't want to deal with the confrontation and always being told that I'm wrong without any explanation. It was just very discouraging." 
In other situations, mentors appeared to question the students' commitment to their programs and to their degrees. Laurel described how her mentor's comments made her feel unmotivated and discouraged her from viewing herself as an academic:

He told me that he thought I wasn't going to graduate and that he thought that he wanted my $\mathrm{PhD}$ more than I want my own $\mathrm{PhD}$, which I think is one of the worst insults that I've ever heard. Coming off of the fact that I had been struggling so hard to pass my qualifying exam, to hear that I'm not going to graduate was a really hard thing and exactly the opposite of what motivates me. I am not motivated by fear or by stress, I'm motivated by opportunity. Him telling me that I'm not going to graduate made me want to work less hard.

Poor Relationship Quality. Nearly half of the doctoral students in our sample $(n=19)$ felt that their mentoring relationships were generally of poor quality or lacked positive relational elements (e.g., empathy, reciprocity, respect) or that they did not have a strong personal attachment or connection with their mentors. Some mentees reported that their relationships with their mentors were practically nonexistent, while others noted a lack of closeness or trust. For instance, Thea recalled that her relationship with her mentor felt insubstantial, explaining that "Compared to a lot of people I wouldn't call it bad. It wasn't terrible, it just wasn't great. It just, it was almost like he wasn't a mentor to me at all."

Often mentees indicated that the mentoring relationship felt compulsory or lacked depth beyond a supervisory or formally assigned relationship. Ash described:

I just get the feeling sometimes like that she couldn't care less about what I'm really doing in the lab as long as it produces results. This lab is pretty well funded and there are a lot of students that would like to get into it ... Sometimes I feel easily replaceable and that she really couldn't care less ... If I told her tomorrow that I was leaving the lab, she probably wouldn't bat an eye, at least to my face.

Some participants felt that their mentors tried to resolve their relational issues, but that their attempts were not successful and contributed to future issues. For example, Lily likened her relationship with her mentor to that of an abusive romantic relationship:

Whenever we had big fights ... she would say "Let's go out for dinner." She would always be nice to me right after a fight ... She'd listen and apologize but then she'd do the same thing again. Looking back on it is ridiculous ... It was like how you bring flowers to your girlfriend after you beat them up. Not joking, that's really what it was like. But then she'd do the same thing again and again.

Other doctoral students felt that their mentors were not sincere or believable, which undermined trust in their relationships. Lee described how his mentoring relationship was characterized by distrust:

If I ask [my mentor] a question and he tells me an answer, and then the next day he completely forgets the way he worded things. Now I've learned to write things down, repeat it to him, and he says "yes." One day he told me straight up that I am lying, that I had made it up, and I was like "I literally wrote down word for word what you told me to do."... So I distrust him about certain things.

Collectively, the dyadic system results indicate that all doctoral students in our sample experienced one or more problems with the quality of their mentoring relationships and the support they received from their mentors.

\section{Ontogenic System}

The ontogenic system is characterized by individual-level characteristics and behaviors of the mentor as perceived by the mentee. We observed six main forms of ontogenic-level negative mentoring experiences: deceit, inaccessibility, limited expertise, limited interpersonal abilities, problematic supervisory styles, and unequal treatment.

Deceit. About a quarter of participants in our sample $(n=12)$ described instances when their mentors behaved or acted in ways that misrepresented or "hid" information about research obligations, expectations, lab or work norms, and career motivations from their mentees. Doctoral students recognized that these actions had occurred after they discovered information that contradicted their mentors' justifications or explanations. In many situations, participants felt that these actions were related to a mentor's own career motivations or outcomes (e.g., tenure, sabbatical, professional moves, retirement, authorship decisions). These behaviors often led to strained relationships, because mentees felt that they were not trusted by or able to trust their mentors. Ash described how his mentor moved their laboratory to a more prestigious institution, providing no information about the move until the plans had already been solidified:

A week before lab meeting, [my mentor] said, "I have some lab business to discuss after lab meeting next week, so please make sure to attend." I didn't think much of it ... but the rumor mill got churning and some people figured it out that somehow she was moving to another campus, a more prestigious campus. I heard those rumors and thought, "There's no way. That would be crazy," but that's what it ended up being. This must have been all but certain for a matter of months and she didn't share anything about the process or the possibility of it with those of us in the lab who it really impacts ... It was really a bummer to feel that way ... like this important information had been hidden from us because it wasn't necessary to our productivity I guess, but it is necessary for our future planning and especially for me.

Inaccessibility. Almost all of the doctoral students $(n=38)$ in our sample reported that they did not receive sufficient attention from their mentors, primarily because they perceived their mentors were too busy with other professional obligations, their mentors had personal issues that demanded their attention, or that their mentors were emotionally unavailable. Graduate students felt that their mentors' busyness or personal issues compromised the quality of their relationships and their mentors' capacity to provide support. Some participants 
reported that their mentors had professional obligations or competing demands that severely constrained the amount of time they were able to devote to their mentees. Others noted that their mentors had administrative responsibilities (e.g., department head, graduate coordinator) that made them "extremely busy." Some described how their mentors were chronically inaccessible due to conference travel, fieldwork, and other responsibilities of their position (e.g., grant writing, teaching). Addison remarked:

He had a lot of administrative duties. We would see him in the lab maybe like three times a year ... His presence in the lab itself was minimal, and I started seeing him one-on-one a lot less because he was physically out of the country. He'd be giving talks and he would just have these other responsibilities.

Mentees also attributed their mentors' inaccessibility to personal demands such as family issues, emotional difficulties, and life-changing situations (e.g., marital problems, mental health issues, moving), which impacted their ability to mentor effectively. Doctoral students recognized that these issues were often outside of their mentors' control, but they also expressed frustration that these personal experiences negatively impacted their mentors' work performance and accessibility. Some participants felt that their mentors were "just too overwhelmed to be a proper mentor" or were known to "fall asleep [during lab meetings] because [they were] so exhausted from everything." Heather described how her mentor's role as the director of a graduate program impacted her ability to provide effective mentoring support:

She was just super removed from lab, as far as her [office] location and that her focus was on the master's program and not her $\mathrm{PhD}$ students ... Each time it was just a different excuse. First, it was the master's program. Then it was health issues with her parents. And then it was other stuff with her husband and her kids. And now it's like her and her health, so she wants to retire so she can focus on her health. So it's always something outside of the lab that has the priority.

Several participants also described instances when they felt neglected or abandoned when a mentor went on sabbatical. Doctoral students recognized that were expected to be operating predominantly independently during their graduate education, but they also desired periodic guidance and support from their mentors to alleviate feelings of neglect or abandonment. Evan recalled the experience of needing and failing to receive support from his mentor:

He got tenure right at the end of my first year here. He and his wife both did .... and then they both went on a one year long sabbatical ... So that's been difficult. He's been even less responsive. He's been you know, dealing with his own stuff. He's been homeschooling his children the first semester he was over on sabbatical in Europe, so that was taking up a ton of this time. He's collaborating with other universities.

In addition to being physically inaccessible, mentors were perceived as emotionally unavailable or inaccessible by the majority of our participants. Specifically, doctoral students felt that when they confided in or revealed something emotionally sensitive to their mentors (e.g., personal stressors, concerns over qualifying examinations), their mentors appeared to lack empathy or seemed inattentive or disinterested. When some doctoral students confided their concerns with their mentors, they felt they received an emotionally inappropriate or invalidating response. They expressed disappointment in not being able to rely on their mentors for support, as Makayla remarked:

I got divorced and it was a terrible, terrible time ... I wanted to take a bit of a break. [My mentor] took me to coffee saying that she'd gotten divorced as well when she was younger and she wanted to talk about it. I kind of thought, because I am an idiot, "Oh look a human side. This is great." But no, the coffee was to explain to me how this was the wrong time to take time off because I really had to hunker down and work ... bury myself in work to make myself feel better. That was her advice. It did not make me feel any better ... Apparently, she was relating to me by saying, "I've been in the same situation as you and this is how you fix it-by working 12-hour days until I tell you to stop." That's not good advice. I felt that she was in a position of power and a position to help me, and she chose not to.

Limited Expertise. More than half of the doctoral students in our sample $(n=23)$ noted that their mentors did not have sufficient knowledge, skills, or abilities to provide effective guidance. Some participants described situations in which their mentors were not familiar with an experimental technique, methodology, or the relevant literature necessary for their research. Others spoke more generally, noting that their mentors appeared to not have sufficient knowledge to provide substantive guidance about the research, as Anny explained:

[My mentor] had many projects in the lab, like most PIs do. He put me on the one that he cares the least about and knows the least about. I think that was a mistake. Usually PIs know at least a little bit about each project. Looking back, I don't know why he even has that project going on because he knows nothing about it ... He didn't know any of the relevant literature. I would be stuck on something and try to figure it out and I'd tell him and he would just not know. And he would never admit [that he didn't know] it either.

Other doctoral students felt that their mentors had minimal expertise in the practice of mentoring, which limited their ability to effectively support graduate students. Some students attributed this to the fact that their mentors were new faculty members and that they were the first graduate student to join their research groups. Others felt that their mentors generally had little knowledge or had not received training or professional development on how to mentor graduate students. For example, Laurel described how her mentor's inexperience contributed to a marginal mentoring experience:

I think his poor mentorship is not because he's a bad person or a bad guy, I think he's just so new that he couldn't even fathom that people approach problems in a different way than him ... He's actually commented and [said that] it's actually taken him a long time to realize that each student needs their own 
things and to be mentored in their own ways. I think a lot of our conflict was driven by his lack of mentor experience. He's even admitted that he had received no training in how to be a mentor. His post doc mentor matched the style that he needed, so he's never thought about other mentorship styles.

Limited Interpersonal Abilities. The majority of participants in our sample $(n=34)$ felt that their mentors were interpersonally maladroit or ineffective in interacting, communicating, or working with others as a result of limited social skills. Some instances involved mentors engaging in behaviors inappropriate for the workplace, such as discussing romantic interests or over-sharing details from their personal lives. For example, Gabriela explained how her mentor confided confidential information about his personal life with her:

[My mentor] just kept telling me about all this stuff that he was going through. Some of which was very inappropriate. Like "I don't know if I love my wife anymore"... I should have had the nerve to stop him and tell him like, "Hey this is uncomfortable, I don't want to know this."

Gabriela's mentor continued to overstep professional boundaries by providing unsolicited advice on her personal life, saying, “'You should date this guy,' and, 'You should see this other person.' And, [my mentor] said 'Oh I'm going to try to date this grad student.' Telling me all these things. And I was like, 'Stop, please."

Other participants described how their mentors made inappropriate jokes and comments, swore, or used repugnant language. For example, doctoral students recalled how their mentors were known to explicitly promote their personal opinions and make statements that were perceived to be uncalled for in the workplace, such as "you shouldn't have kids while in graduate school" or that "anyone who works in industry is basically a blood-sucking leech." In a particularly extreme situation, a doctoral student recalled how her mentor made an extremely vulgar remark and referred to her as "a sexual assault magnet."

Other instances of interpersonal incompetence occurred when doctoral students felt that their mentors had personality traits, attitudes, or behaviors that undermined their relationships. For example, participants described their mentors as condescending, defensive, dismissive, hot-tempered, narcissistic, or rude. In other cases, doctoral students believed that their mentors had underdeveloped "soft skills" or were just generally difficult to work with. Some participants described these traits being persistent throughout the mentoring relationship, while others felt that a mentor's behavior had progressively deteriorated or changed since the student had initially joined the lab. Other participants expressed frustration because their mentors appeared to have multiple, oscillating personalities that were unpredictable. For example, Steven recalled how his mentor's behavior appeared to be influenced by interpersonal or environmental stresses, which made it difficult for him to ask her for support:

She runs very hot and cold ... Some days she would come in and she'd be just a lovely person. She'd be fine to work with.
But then, the next day, it'd be the complete opposite person. It was this ticking time bomb of anger and frustration that we would try to work around. I would dread coming into the office, thinking, is today going to be the day she's going to blow up on me for something? There was that constant fear and level of anxiety coming into the office every day and potentially dealing with that.

Doctoral students also described how their mentors behaved in passive-aggressive ways or were known to make indirect or subtle disparaging remarks (i.e., microaggressions). These situations made it challenging for mentees to engage or interact with their mentors. Adrianna, an international student, described one situation when she had wanted to return to her home country for holiday break, and her mentor initially agreed. However, when Adrianna returned, she explained how her mentor appeared to be irritated that she had spent time out of lab:

After I came back, she was very annoyed. Really openly annoyed at me for quite some time. It was definitely a stressful period for me. She's my advisor, and of course I needed to talk to her, but the conversations were always very tense. It's not like she ever openly told me how annoyed she was, but everyone in the lab could tell.

Problematic Supervisory Styles. Almost all of the doctoral students in our sample $(n=34)$ described problematic supervisory styles, which included abusive supervision, hands-off supervision, and micromanagement. All three styles were perceived as ineffective or detrimental, undermining the formation of a healthy and productive working relationship. More than half of the doctoral students in our study reported forms of abusive supervision (Tepper et al., 2017), such as yelling, name calling, credit taking, punishment, intimidation, and coercion, as well as making explicit or implicit threats and encouraging competition between lab members. Makayla explained how her mentor would engage in abusive behaviors such as yelling, aggressive outbursts, and accusations:

She'd call you incompetent all the time, at least on a weekly basis ... She would explode, with this sort of tirade where she'd call you stupid or incompetent ... She'd occasionally accuse you of making things up when they weren't working, which makes no sense because if you were going to make it up, surely, you'd make it up that it was working!... She also called me an idiot a couple of times ... sometimes I am an idiot, but I sort of had this notion that you can't call people idiots when you're working, but clearly that was not the case. She'd also call you stupid. She'd call you a failure.

Other doctoral students reported that their mentors were "hands-off," providing too little guidance or supervision on their research. These mentees expressed the need for more management to help them stay on track and make progress in their research. Although they appreciated the opportunity to function autonomously, they also felt that their mentors did not care about them or their work. For example, Evan wished that his mentor was more involved: 
I think that one of the main things that was damaging to me and also to other graduate students is that he's been so handsoff. I am not saying that I need a babysitter and that I need a super hard deadline for me to have this paragraph of my manuscript [written] and this section of my manuscript to be done by. I don't need to be micromanaged, but I need to be paid attention to.

Yet other doctoral students expressed that their mentors engaged in "micromanagement"-being too involved in the day-to-day operations or too controlling of even straightforward tasks. Some doctoral students described how their mentors' curiosity and excitement over new findings, which was likely well intentioned, was perceived to be intrusive and added unnecessary stress for the student. Aaron explained:

As I'm developing the westerns, he's standing... looking over my shoulder and watching them develop. So I have to process this mentally for myself but also try to explain to him what we're looking at in real time. Even before I have a chance to look and think about the data, I have to be able to interpret it and explain it and prove it to him.

Unequal Treatment. More than a quarter of participants $(n=$ 14) described how their mentors treated individuals either more or less favorably on the basis of their personal characteristics, resulting in differential treatment. Doctoral students explained that their mentors appeared to treat certain individuals less favorably because of their race, gender, or other personal characteristics or because of their professional interests or aspirations (e.g., teaching interests, nonacademic careers). We distinguished these experiences from macro-level phenomena (e.g., gatekeeping, role tension), because doctoral students described these experiences arising from the direct actions of their mentors, rather than explicit departmental or cultural norms and practices that resulted in unequal treatment. Some participants described how their mentors made blatant, prejudicial statements such as, "[You're] a Latino, you'll have to work twice as hard to prove yourself." Other mentors appeared to pass judgment on their mentee's lifestyle choices, such as having children or getting married while in graduate school. For example, Clove explained, "When we talked about my son, he'd always be like, 'It's unfortunate that you have this burden that makes it so that you can't get work done.' He thought I was not as effective as a researcher because I had a child."

Other doctoral students described how their male mentors appeared to have a closer, more casual relationship with their male mentees compared with their female mentees. Thea recognized that her mentor was likely trying to behave appropriately, but she expressed how these attempts resulted in differential treatment:

[Male graduate student] would house sit for [my mentor] while he was gone. They would go on trips to meet collaborators and conferences together ... When they were at conferences, they would go out to get a beer together... My mentor and [graduate student] would always have hang out time with the bros and I never saw my mentor interact that way with one of his female students ... I think he was so afraid of being sexist that he ended up actually being sexist. He was so afraid of crossing a line that shouldn't be crossed that he instituted a barrier for his female students that he didn't institute for his male students. I think it's because he was trying to do the right thing ... But there was a wall I hit as a female student ... I know he's coming from what he thinks is best. He really thinks that putting up these barriers between himself and his female graduate students is good. But he doesn't realize that it's bad when you're not doing it with all of your students.

Some doctoral students described how their mentors appeared to have preferences or played favorites among individuals. Participants identified these instances of favoritism because their mentors gave special or preferential treatment to others for no apparent reason. For example, Anny recounted how students in her lab were viewed and valued based on their position, "My mentor thought that MD students were smarter than PhD students ... none of the MDs in the lab had lab duties - the lab chores would be assigned to $\mathrm{PhD}$ students and postdocs but not to anyone who was a MD." Some doctoral students described how their mentors had more stringent expectations for them, but other members of the lab were allowed to perform or operate below these expectations. For example, Britney described:

My mentor always had a favorite ... being the favorite meant that [other graduate student] could get away with anything. She could do whatever she wanted. She could just not show up and she wouldn't get in trouble ... Anything [other graduate student] did, even if it was small, was wonderful and worth praise while everyone else in the lab got ignored.

Altogether, the ontogenic-level results indicate that mentees suffer from a range of mentor behaviors, even behaviors that may be well intentioned.

\section{DISCUSSION}

Here we identify and describe the negative mentoring that life science doctoral students experience with their research mentors. We found that mentoring relationships during graduate education, like all interpersonal relationships (Duck, 1994; Scandura, 1998), can become dysfunctional or have problematic elements. Prior research has dichotomized negative mentoring experiences in terms of the effects on mentees' career or psychosocial outcomes (Scandura, 1998). However, doctoral students in our sample described how their negative experiences had both detrimental career and psychosocial effects, rather than one or the other. For example, doctoral students whose mentors prevented them from presenting their research at academic conferences indicated that they missed opportunities for career development and networking (i.e., career effects) and that this undermined their confidence and identity as a scientist (i.e., psychosocial effect). It is possible that doctoral students experience both career and psychosocial effects of negative mentoring because of their unique position as students and employees. Because they are students, doctoral students may need more space to learn, make mistakes, and get feedback and reassurance than employees. Yet they also need support related to their career advancement like employees.

Prior research has also dichotomized negative mentoring experiences in terms of mentee perceptions of mentors' good or bad intent (Scandura, 1998). However, doctoral students in our 
sample typically did not focus on mentor intent. In fact, doctoral students attributed at least some mentor behaviors and relationship shortcomings to factors at the level of research groups, departments, organizations, and academic research (Figure 1), even though they were not prompted to do so. For instance, doctoral students perceived there was little if any incentive to provide quality mentoring (macro), which meant there was no expectation for their mentors to be accessible (ontogenic). The mentor's inaccessibility led to lack of career and psychosocial support (dyadic) that continued because insufficient structure was in place at the program level (micro) to provide other forms of support to the student or accountability from the mentor. These results draw attention to the fact that, even though destructive behaviors of mentors are not excusable, a faculty member is just one individual within a larger ecosystem, and doctoral students are observing this during their research training. Other findings from our study suggest that there are unique constraints mentors face in academic settings that may hinder their abilities to engage in high-quality mentoring relationships. For example, many doctoral students described their mentors as having little mentoring competence or training (ontogenic). This contributed to poor attempts at mentor responsiveness to mentee needs, limited overall relationship quality (dyadic), and continuing conflicts within research groups (micro). Furthermore, these situations led to tension regarding the purpose of graduate education if mentees expressed interest in non-research related areas (macro). This is concerning, because doctoral students may be more hesitant to report and address mentoring issues if they perceive these experiences are integral elements of a larger system that is beyond their control to change.

\section{Implications for Mentors, Programs, and Institutions}

Our results provide some evidence that macro- and micro-level actions are needed to achieve ontogenic- and dyadic-level improvements. For instance, graduate programs could equip mentors and mentees with mentoring maps that make explicit the variety of mentoring functions doctoral students need and provide a structure for identifying a collection of individuals who can provide mentoring support (Montgomery, 2017; NASEM, 2019). Mentoring maps may also help mentors recognize and make transparent to their mentees that they have the latitude to find other mentors who are able to give them support, professional assistance, consultation, or guidance that the mentors themselves are not able to provide. For example, a mentor who is not familiar with a technique or method (i.e., limited expertise) could connect a mentee with an individual with suitable expertise. It is important to note that the research advisor is still fulfilling the networking function of mentoring by helping the mentee recognize the gap and find a suitable mentor to address it. Several studies have shown that having a "constellation of mentors" who fulfill different needs can lead to more positive overall mentoring experiences and mentee outcomes (de Janasz and Sullivan, 2004; Baugh and Scandura, 1999; Feldon et al., 2019; Blaney et al., 2020).

Some of the forms of negative mentoring reported here could be addressed by widespread participation in mentoring professional development, such as Entering Mentoring (CIMER Project, https://cimerproject.org/entering-mentoring/; Pfund et al., 2006, 2014). For instance, issues at the ontogenic and micro levels, such as deceit and social undermining, relate to the component of Entering Mentoring on communicating effectively. Issues related to mentor accessibility, hands-off supervision, micromanagement, and career and psychosocial support are addressed in the component of Entering Mentoring on setting expectations. These curricular materials provide real-life scenarios that help mentors recognize problematic mentoring dynamics and develop strategies for addressing them or avoiding them altogether, such as by using mentoring compacts and expectation-setting tools. Furthermore, Entering Mentoring is designed to equip mentors with tools and approaches to negotiate situations with mentees, rather than stipulating any single way of working with all mentees, who will come to a mentoring relationship and their graduate education with different needs, interests, expectations, and priorities. For instance, some mentees might desire more input and oversight, while others might want more independence. Entering Mentoring addresses how to align one's supervisory styles to meet particular mentee needs and desires (more or less supervision), including using individual development plans to create mutual expectations for graduate student progress and developing clear and shifting supervisory style over the course of a doctoral student's education (from more to less supervision; Clifford et al., 2013; Vanderford et al., 2018). Although there is some evidence of the effectiveness of Entering Mentoring (Pfund et al., 2014), future research is needed to determine whether participating in mentoring professional development mitigates or prevents negative mentoring experiences.

Some forms of negative mentoring reported here may not be alleviated with time-limited professional development. Resources, support, and interventions over time will likely be necessary to address deeper-seated issues that have the potential to cause greater harm. For example, doctoral students in our sample reported unprofessional mentor behaviors that may require intercession at multiple levels over time (e.g., limited interpersonal abilities, abusive supervision). Educational interventions that equip individuals in positions of power (e.g., graduate coordinators, program directors, department heads) with skills to identify poor behaviors and engage in difficult conversations to mitigate it have effectively reduced workplace incivility (Stoddard, 2017; Howard and Embree, 2020). Such interventions could be adapted and deployed in academic research settings and tested for their effectiveness in reducing graduate negative mentoring experiences. Although such interventions may seem costly, they may ultimately reduce the cost of bad behavior (Porath and Pearson, 2010), especially the loss of graduate talent from the STEM workforce. In addition, some of the behaviors reported here may qualify as human resources violations (e.g., workplace harassment) or violations of nondiscrimination and anti-harassment policies (e.g., unfair treatment). Institutions should put structures in place to ensure graduate students are informed about what constitutes such violations and have access to support and protection for reporting potential violations.

Other negative mentoring experiences reported here indicate that students may expect their research advisor to provide all of the support they need to be successful in their research and their graduate programs. For instance, more than half of the doctoral students in our study noted that their mentors' expertise was insufficient to provide guidance on their doctoral 
research. This experience may be due to a mismatch in expectations. For instance, students may expect their advisors to be able to answer all of their questions, dictate or approve all steps of their research, and provide emotional support when research is not progressing as planned. In contrast, advisors may see their role as being a coach who provides advice on how to find answers and think through possible next steps of the research, but not as the source of all technical expertise or emotional support. Indeed, given that high-quality mentoring involves the provision of a wide range of support (e.g., task assistance, exposure, protection, confirmation, counseling; Eby et al., 2013), it is unreasonable to ask one faculty to operate as a sole mentor to a doctoral student. Again, mentoring maps may be helpful for addressing this by making various mentoring needs transparent for mentors and mentees and providing a structure for mentoring support that is not limited to the dyad. Expectation-setting tools are also likely to be helpful for communicating and coming to consensus about expectations (Moses, 1985).

Different mentorship structures (e.g., co-mentoring, more empowered dissertation committees) and more diffuse funding models (e.g., training grants, departmental fellowships) should be explored for their potential to avoid graduate student reliance on a single faculty mentor. These ideas align with the National Academies' recommendation for improving STEM graduate education by evolving micro-level practices to improve mentorship for doctoral students (NASEM, 2018). These approaches offer the potential to reduce the adverse, macro-level phenomena such as the role tension experienced by graduate students in our sample. Our results also support the recommendation to add micro-level structures that enable meaningful evaluation of mentorship quality and competence in hiring, in annual performance reviews, and for promotion and tenure. Shifts in micro- and macro-level culture regarding the value of effective mentoring will likely be necessary to achieve widespread reduction or prevention of negative mentoring experiences. Lessons learned from efforts to promote undergraduate education reform, including evaluating, incentivizing, and rewarding teaching quality, may offer useful insights for accomplishing this (Kezar, 2014; Corbo et al., 2016).

\section{Implications for Mentees}

These findings should be reassuring to mentees that they are not alone in experiencing negative mentoring. Furthermore, there are tools and strategies that mentees can use to "mentor up," taking a more active role in maximizing and cultivating the quality of their mentoring relationships (Lee et al., 2015). Mentees can mentor up even before they start their doctoral degrees and throughout their programs. For example, doctoral program applicants can use the results reported here to guide their explorations of their programs of interest. They may want to inquire about whether:

- Faculty participate in mentoring professional development or use mentoring tools such as mentoring compacts, expectations scales, and maps.

- Programs provide mentoring professional development and/ or require faculty to complete it.

- Programs have structures in place that enable mentees to report negative mentoring experiences, support mentors and mentees in conflict resolution, and enable mentees to safely transition to more positive mentoring situations if and when needed.

Mentees can also use the results reported here to guide their exploration of mentors and research groups, especially in life science disciplines that include research rotations in the first year. Again, they can ask whether mentors have participated in mentoring professional development or use tools that support high-quality mentoring (Huskins et al., 2011; Clifford et al., 2013; Masters and Kreeger, 2017; Montgomery, 2017; NASEM, 2019). They can ask research group members about the mentors' supervisory styles and whether and how mentors go about providing support that is responsive to individual mentee needs over time. The overarching goal of mentee exploration should not be on finding a single right answer, but rather on finding a fit with what they are seeking from a research advisor as a main, but not only, mentor. Mentees can also learn how to effectively solicit the desired support from their mentors, which can help them maximize the outcomes of their mentoring relationships and may prompt their mentors to provide additional support.

\section{Limitations and Future Research}

Our study has several limitations that should be considered when interpreting the results. Our sample was voluntary and limited in size (40 participants), degree type (doctoral), and discipline (life sciences). We collected data until we reached saturation, but it may be that students who did not volunteer had substantively different experiences that were not reported (e.g., harassment, discrimination, unwanted sexual attention). Another possibility is that some doctoral students expect negative mentoring experiences to be "normal" or anticipated elements of STEM graduate training, and thus not worth reporting. Future research needs to examine negative mentoring experienced by a larger sample of doctoral students from a broader range of disciplines, institution types, citizenship status (i.e., international), degree types (e.g., MS, MD/PhD), and programs (e.g., rotations, direct admit) to determine whether graduate students experience other forms of negative mentoring not observed here.

Our participants were reflective of the national demographics of individuals pursuing life science doctoral degrees, yet only 12 students $(-30 \%)$ who identified as Black, Latinx, or Native American/Native Alaskan participated in our study, and none of our participants identified as gender nonbinary. Current reform efforts aimed at broadening participation advocate for mentoring as a strategy for improving access to and equity of STEM education. Indeed, a growing body of research has shown that quality mentorship during research experiences is important for women and individuals from racial and ethnic backgrounds that have been excluded from STEM (Hurtado et al., 2009; Griffin et al., 2010, 2018; Wilson et al., 2011; Byars-Winston et al., 2015; Lee et al., 2015; Lewis et al., 2016; Aikens et al., 2017; Hernandez et al., 2017; Estrada et al., 2018; Asai, 2020; McGee, 2020). Consequentially, negative mentoring experiences could be disproportionately harming marginalized students. Future research should examine the specific forms of negative mentoring experienced by students from particular racial and ethnic backgrounds and gender identities, including experiences at the intersection of identities. Such 
investigations could provide additional insights on factors contributing to the continued underrepresentation of marginalized individuals in STEM fields.

Our study was cross-sectional and retrospective in nature, relying on doctoral students' recollections of their experiences and outcomes. Thus, the results may be subject to recall bias or conjecture about potential causes of negative experiences. Furthermore, studies from workplace settings have demonstrated that negative mentoring experiences are predictive of mentee turnover intentions (Eby and Allen, 2002). It is possible that doctoral students who left their graduate programs prematurely because of negative mentoring may have experienced considerably different forms of negative mentoring that were not captured in our study. Future research should make use of longitudinal study designs and methods, as well as established measures of graduate student outcomes, to track negative mentoring experiences over time, identify other potential forms of negative mentoring, and determine their effects. Results from this research would be helpful for identifying key points during graduate education when students might need more or less support and for tailoring program resources accordingly.

We elected to study mentees' perspectives and opted not to collect data from mentors because prior research has found that mentee perceptions are predictive of their outcomes, regardless of mentor intentions or perspectives (Scandura, 1998; Eby and Allen, 2002; Eby et al., 2008a, 2010; Limeri et al., 2019). It is important to note that mentoring is an interpersonal relationship involving two parties. Studies from workplace settings have found that mentors also experience "negative mentoring" from mentees (Eby and McManus, 2004). Future studies should examine negative mentoring experiences from the mentor perspective to understand how mentors might experience and be affected by negative mentoring.

We made the post hoc decision to use ecological systems theory to interpret our data rather than collecting these data from all mentees or from programs and institutions directly. Future research should examine micro- and macro-level phenomena more systematically and directly to understand their influence on the occurrence and impacts of doctoral students' negative mentoring experiences. Results of this work could yield further insight into micro- and macro-level levers for change.

Finally, additional research is necessary to determine the prevalence of negative mentoring experiences and to characterize their causes and effects for doctoral students in STEM fields. A psychometrically sound, quantitative measure of graduate negative mentoring is needed to collect data from a sufficiently large and representative sample to determine the generalizability of our findings. The results presented here should be sufficient for identifying and defining the content domain of the construct of graduate negative mentoring experiences as a first step toward developing a quantitative measure (American Educational Research Association, American Psychological Association, National Council on Measurement in Education \& Joint Committee on Standards for Educational \& Psychological Testing, 2014; Bandalos, 2018). Once developed, the measure could be used to examine the base rates of negative mentoring at the program and institution level and to identify the impacts of negative mentoring, including whether and how mentees from different sociodemographic backgrounds experience neg- ative mentoring differently. The proposed measure could be used to determine antecedents and correlates of negative mentoring experiences and to characterize how these experiences manifest and change over the course of doctoral mentoring relationships. Such a measure could also be used to test the effects of the interventions, such as mentee and mentor professional development as well as changes in program and institutional structures intended to improve mentorship.

\section{ACKNOWLEDGMENTS}

We thank all of our participants for sharing their experiences and the many individuals who helped with distributing the study information. We also thank members of the Social Psychology of Research Experiences \& Education lab (https:// research.franklin.uga.edu/erindolan), the Biology Education Research Group at the University of Georgia (UGA), and Tessa Andrews, C. J. Tsai, and Lance Wells for feedback that improved our work. We thank Myles Porter, a fellow with the NSF-funded Undergraduate Biology Education Research REU Site (grant no. 1659423), for his assistance in early pilot testing of the ecological systems framework for analysis. This material is based upon work supported by an NSF Graduate Research Fellowship awarded to T.T.T. (grant no. DGE-1842396) and an Innovative \& Interdisciplinary Research Grant from the UGA Graduate School awarded to T.T.T. Undergraduate research assistantships awarded to B.C.H. and J.D.A. were provided by the UGA Center for Undergraduate Research Opportunities. Additional support for this work was provided by the Georgia Athletic Association Professorship in Innovative Science Education, the UGA Departments of Biochemistry \& Molecular Biology and Plant Biology, and the Franklin College of Arts \& Sciences. Any opinions, findings, conclusions, or recommendations expressed in this material are those of the authors and do not necessarily reflect the views of any of the funding organizations. The authors dedicate this work to all graduate students who endure difficult mentoring relationships during their graduate education.

\section{REFERENCES}

Aikens, M. L., Robertson, M. M., Sadselia, S., Watkins, K., Evans, M., Runyon, C. R., ... \& Dolan, E. L. (2017). Race and gender differences in undergraduate research mentoring structures and research outcomes. CBE-Life Sciences Education, 16(2), ar34. https://doi.org/10.1187/cbe.16-07-0211

Allen, H. K., Lilly, F., Green, K. M., Zanjani, F., Vincent, K. B., \& Arria, A. M (2020). Substance use and mental health problems among graduate students: Individual and program-level correlates. Journal of American College Health. https://doi.org/10.1080/07448481.2020.1725020

Allen, T. D., Eby, L. T., Poteet, M. L., Lentz, E., \& Lima, L. (2004). Career benefits associated with mentoring for proteges: A meta-analysis. Journal of Applied Psychology, 89(1), 127-136. https://doi.org/10.1037/00219010.89.1.127

American Educational Research Association, American Psychological Association, National Council on Measurement in Education, and Joint Committee on Standards for Educational \& Psychological Testing (US). (2014). Standards for educational and psychological testing. Washington, DC.

Asai, D. J. (2020). Race matters. Cell, 181(4), 754-757.

Bandalos, D. L. (2018). Measurement theory and applications for the social sciences. New York: Guilford.

Barnes, B. J., \& Austin, A. E. (2009). The role of doctoral advisors: A look at advising from the advisor's perspective. Innovative Higher Education, 33(5), 297-315. https://doi.org/10.1007/s10755-008-9084-x

Baugh, S. G., \& Scandura, T. A. (1999). The effect of multiple mentors on protege attitudes toward the work setting. Journal of Social Behavior and Personality, 14(4), 503-522. 
Belur, J., Tompson, L., Thornton, A., \& Simon, M. (2018). Interrater reliability in systematic review methodology: Exploring variation in coder decision-making. Sociological Methods \& Research. https://doi.org/ 10.1177/0049124118799372

Blaney, J., Wofford, A., Kang, J., \& Feldon, D. (2020). Mentoring relationships between doctoral students and postdocs in the lab sciences. Studies in Graduate and Postdoctoral Education, 11(3), 263-279.

Bronfenbrenner, U. (1977). Toward an experimental ecology of human development. American Psychologist, 32(7), 513

Byars-Winston, A. M., Branchaw, J., Pfund, C., Leverett, P., \& Newton, J. (2015). Culturally diverse undergraduate researchers' academic outcomes and perceptions of their research mentoring relationships. International Journal of Science Education, 37(15), 2533-2554. https://doi.or $\mathrm{g} / 10.1080 / 09500693.2015 .1085133$

Chandler, D. E., Kram, K. E., \& Yip, J. (2011). An ecological systems perspective on mentoring at work: A review and future prospects. Academy of Management Annals, 5(1), 519-570. https://doi.org/10.1080/19416520.2 011.576087

Clark, R. A., Harden, S. L., \& Johnson, W. B. (2000). Mentor relationships in clinical psychology doctoral training: Results of a national survey. Teaching of Psychology, 27(4), 262-268. https://doi.org/10.1207/ S15328023TOP2704_04

Clifford, P. S., Fuhrmann, C. N., Lindstaedt, B., \& Hobin, J. A. (2013). An individual development plan will help you get where you want to go. The Physiologist, 56(2), 43-44.

Corbo, J. C., Reinholz, D. L., Dancy, M. H., Deetz, S., \& Finkelstein, N. (2016) Framework for transforming departmental culture to support educational innovation. Physical Review Physics Education Research, 12(1), 010113. https://doi.org/10.1103/PhysRevPhysEducRes.12.010113

Cortina, L. M., Magley, V. J., Williams, J. H., \& Langhout, R. D. (2001). Incivility in the workplace: Incidence and impact. Journal of Occupational Health Psychology, 6(1), 64

Cronan-Hillix, T., Gensheimer, L. K., Cronan-Hillix, W. A., \& Davidson, W. S. (1986). Students' views of mentors in psychology graduate training. Teaching of Psychology, 13(3), 123-127. https://doi.org/10.1207/s15328023top1303_5

de Janasz, S. C., \& Sullivan, S. E. (2004). Multiple mentoring in academe: Developing the professorial network. Journal of Vocational Behavior, 64(2), 263-283. https://doi.org/10.1016/j.jvb.2002.07.001

Duck, S. (1994). Stratagems, spoils and the serpent's tooth: On the delights and dilemmas of personal relationships. In The dark side of interpersonal communication (pp. 3-24). Hillsdale, NJ: Erlbaum.

Duffy, M. K., Ganster, D. C., \& Pagon, M. (2002). Social undermining in the workplace. Academy of Management Journal, 45(2), 331-351. JSTOR. https://doi.org/10.2307/3069350

Eby, L., Allen, T. D., Hoffman, B. J., Baranik, L. E., Sauer, J. B., Baldwin, S., ... \& Evans, S. C. (2013). An interdisciplinary meta-analysis of the potential antecedents, correlates, and consequences of protégé perceptions of mentoring. Psychological Bulletin, 139(2), 441-476. https://doi. org/10.1037/a0029279

Eby, L., Evans, S. C., Ragins, B. R., Eby, L. T., Durley, J. R., Evans, S. C., \& Ragins, B. R. (2008a). Mentors' perceptions of negative mentoring experiences: Scale development and nomological validation. Journal of Applied Psychology, 93(2), 358-373.

Eby, L. T., \& Allen, T. D. (2002). Further investigation of protégés' negative mentoring experiences: Patterns and outcomes. Group \& Organization Management,27(4),456-479.https://doi.org/10.1177/1059601102238357

Eby, L. T., Allen, T. D., Evans, S. C., Ng, T., \& DuBois, D. L. (2008b). Does mentoring matter? A multidisciplinary meta-analysis comparing mentored and non-mentored individuals. Journal of Vocational Behavior, 72(2), 254-267. https://doi.org/10.1016/j.jvb.2007.04.005

Eby, L. T., Butts, M. M., Durley, J., \& Ragins, B. R. (2010). Are bad experiences stronger than good ones in mentoring relationships? Evidence from the protégé and mentor perspective. Journal of Vocational Behavior, 77(1) 81-92. https://doi.org/10.1016/j.jvb.2010.02.010

Eby, L. T., \& Dolan, E. L. (2015). Mentoring in postsecondary education and organizational settings. In Hartung, P. J., \& Savickas, M. L. (Eds.), APA handbook of career intervention, Vol. 2, Applications (pp. 383-395). Washington, DC: American Psychological Association. https://doi.org/ 10.1037/14439-028
Eby, L. T., \& McManus, S. E. (2004). The protégé's role in negative mentoring experiences. Journal of Vocational Behavior, 65(2), 255-275. https://doi .org/10.1016/j.jvb.2003.07.001

Eby, L. T., McManus, S. E., Simon, S. A., \& Russell, J. E. A. (2000). The protege's perspective regarding negative mentoring experiences: The development of a taxonomy. Journal of Vocational Behavior, 57(1), 1-21. https:// doi.org/10.1006/jvbe.1999.1726

Eby, L. T., \& Robertson, M. M. (2020). The psychology of workplace mentoring relationships. Annual Review of Organizational Psychology and Organizational Behavior, 7(1), 75-100. https://doi.org/10.1146/ annurev-orgpsych-012119-044924

Estrada, M., Hernandez, P. R., \& Schultz, P. W. (2018). A longitudinal study of how quality mentorship and research experience integrate underrepresented minorities into STEM careers. CBE-Life Sciences Education, 17(1) ar9. https://doi.org/10.1187/cbe.17-04-0066

Evans, T. M., Bira, L., Gastelum, J. B., Weiss, L. T., \& Vanderford, N. L. (2018). Evidence for a mental health crisis in graduate education. Nature Biotechnology, 36(3), 282-284. https://doi.org/10.1038/nbt.4089

Feldon, D. F., Litson, K., Jeong, S., Blaney, J. M., Kang, J., Miller, C., ... \& Roksa, J. (2019). Postdocs' lab engagement predicts trajectories of PhD students' skill development. Proceedings of the National Academy of Sciences USA, 116(42), 20910-20916. https://doi.org/10.1073/pnas .1912488116

Garvey, J. C., Hart, J., Metcalfe, A. S., \& Fellabaum-Toston, J. (2019). Methodological troubles with gender and sex in higher education survey research. Review of Higher Education, 43(1), 1-24. https://doi.org/10.1353/ rhe.2019.0088

Golde, C. M. (1998). Beginning graduate school: Explaining first-year doctoral attrition. New Directions for Higher Education, 1998(101), 5564. https://doi.org/10.1002/he.10105

Golde, C. M. (2005). The role of the department and discipline in doctoral student attrition: Lessons from four departments. Journal of Higher Education, 76(6), 669-700. https://doi.org/10.1353/jhe.2005.0039

Goodyear, R. K., Crego, C. A., \& Johnston, M. W. (1992). Ethical issues in the supervision of student research: A study of critical incidents. Professional Psychology: Research and Practice, 23(3), 203-210. https://doi .org/10.1037/0735-7028.23.3.203

Griffin, K., Baker, V., O'Meara, K., Nyunt, G., Robinson, T., \& Staples, C. L. (2018). Supporting scientists from underrepresented minority backgrounds: Mapping developmental networks. Studies in Graduate and Postdoctoral Education, 9(1), 19-37. https://doi.org/10.1108/SGPE -D-17-00032

Griffin, K. A., Pérez, D., Holmes, A. P. E., \& Mayo, C. E. P. (2010). Investing in the future: The importance of faculty mentoring in the development of students of color in STEM. New Directions for Institutional Research, 2010(148), 95-103. https://doi.org/10.1002/ir.365

Guest, G., Bunce, A., \& Johnson, L. (2006). How many interviews are enough? An experiment with data saturation and variability. Field Methods, 18(1) 59-82. https://doi.org/10.1177/1525822X05279903

Hernandez, P. R., Bloodhart, B., Barnes, R. T., Adams, A. S., Clinton, S. M., Pollack, I., ... \& Fischer, E. V. (2017). Promoting professional identity, motivation, and persistence: Benefits of an informal mentoring program for female undergraduate students. PLOS ONE, 12(11), e0187531. https://doi .org/10.1371/journal.pone.0187531

Hish, A. J., Nagy, G. A., Fang, C. M., Kelley, L., Nicchitta, C. V., Dzirasa, K., \& Rosenthal, M. Z. (2019). Applying the stress process model to stressburnout and stress-depression relationships in biomedical doctoral students: A cross-sectional pilot study. CBE-Life Sciences Education, 18(4), ar51. https://doi.org/10.1187/cbe.19-03-0060

Howard, M. S., \& Embree, J., L. (2020). Educational intervention improves communication abilities of nurses encountering workplace incivility Journal of Continuing Education in Nursing, 51(3), 138-144.

Hsieh, H.-F., \& Shannon, S. E. (2005). Three approaches to qualitative content analysis. Qualitative Health Research, 15(9), 1277-1288. https://doi .org/10.1177/1049732305276687

Hurtado, S., Cabrera, N. L., Lin, M. H., Arellano, L., \& Espinosa, L. L. (2009) Diversifying science: Underrepresented student experiences in structured research programs. Research in Higher Education, 50(2), 189 214. https://doi.org/10.1007/s11162-008-9114-7 
Huskins, W. C., Silet, K., Weber-Main, A. M., Begg, M. D., Fowler, J., Vance, G., .. \& Fleming, M. (2011). Identifying and aligning expectations in a mentoring relationship. Clinical and Translational Science, 4(6), 439447. https://doi.org/10.1111/j.1752-8062.2011.00356.x

Hyun, J. K., Quinn, B. C., Madon, T., \& Lustig, S. (2006). Graduate student mental health: Needs assessment and utilization of counseling services. Journal of College Student Development, 47(3), 247-266. https://doi. org/10.1353/csd.2006.0030

Johnson, W. B., \& Huwe, J. M. (2002). Toward a typology of mentorship dys function in graduate school. Psychotherapy: Theory, Research, Practice Training, 1, 44.

Kalbfleisch, P. J. (1997). Appeasing the mentor. Aggressive Behavior, 23(5), 389-403. https://doi.org/10.1002/(SICI)1098-2337(1997)23:5<389::AIDAB7>3.0.CO;2-D

Kezar, A. (2014). higher education change and social networks: A review of research. Journal of Higher Education, 85(1), 91-125. https://doi .org/10.1353/jhe.2014.0003

Kolb, S. M. (2012). Grounded theory and the constant comparative method: Valid research strategies for educators. Journal of Emerging Trends in Educational Research \& Policy Studies, 3(1), 83-86.

Kram, K. E. (1983). Phases of the mentor relationship. Academy of Management Journal, 26(4), 608-625. https://doi.org/10.2307/255910

Lee, S. P., McGee, R., Pfund, C., \& Branchaw, J. (2015). Mentoring up: Learning to manage your mentoring relationships. The Mentoring Continuum: From Graduate School through Tenure (pp. 133-154). Syracuse, NY Graduate School Press of Syracuse University.

Levecque, K., Anseel, F., De Beuckelaer, A., Van der Heyden, J., \& Gisle, L. (2017). Work organization and mental health problems in PhD students. Research Policy, 46, 868-879. https://doi.org/10.1016/j.respol 2017.02.008

Lewis, V., Martina, C. A., McDermott, M. P., Trief, P., Goodman, S. R., Morse, G. D., ... \& Ryan, R. M. (2016). A randomized controlled trial of mentoring interventions for underrepresented minorities. Academic Medicine, 91(7), 994-1001. https://doi.org/10.1097/ACM.0000000000001056

Limeri, L. B., Asif, M. Z., Bridges, B. H. T., Esparza, D., Tuma, T. T., Sanders, D. ... \& Dolan, E. L. (2019). "Where's my mentor?!" Characterizing negative mentoring experiences in undergraduate life science research. CBE-Life Sciences Education, 18(4), ar61. https://doi.org/10.1187/cbe.19-02 $-0036$

Lincoln, Y. S., \& Guba, E. G. (1985). Establishing trustworthiness. Naturalistic Inquiry, 289, 331.

Lovitts, B. E. (2002). Leaving the ivory tower: The causes and consequences of departure from doctoral study. Lanham, MD: Rowman \& Littlefield.

Lunsford, L. (2012). Doctoral advising or mentoring? Effects on student outcomes. Mentoring \& Tutoring: Partnership in Learning, 20(2), 251-270.

Maher, M. A., Wofford, A. M., Roksa, J., \& Feldon, D. F. (2017). Exploring early exits: Doctoral attrition in the biomedical sciences. Journal of College Student Retention: Research, Theory \& Practice, 1521025117736871 https://doi.org/10.1177/1521025117736871

Masters, K. S., \& Kreeger, P. K. (2017). Ten simple rules for developing a mentor-mentee expectations document. PLOS Computational Biology, 13(9), e1005709. https://doi.org/10.1371/journal.pcbi.1005709

McAllister, C. A., Harold, R. D., Ahmedani, B. K., \& Cramer, E. P. (2009). Targeted mentoring: Evaluation of a program. Journal of Social Work Education, 45(1), 89-104. https://doi.org/10.5175/JSWE.2009.200700107

McGee, E. O. (2020). Black, brown, bruised: How racialized STEM education stifles innovation. Cambridge, MA: Harvard Education Press.

McGee, R., \& Keller, J. L. (2007). Identifying future scientists: Predicting persistence into research training. CBE-Life Sciences Education, 6(4), 316331. https://doi.org/10.1187/cbe.07-04-0020

Merriam, S. B. (1998). Qualitative research and case study applications in education. Revised and expanded from "Case Study Research in Education." San Francisco, CA: Jossey-Bass. bib>

Miles, M. B., Huberman, A. M., \& Saldaña, J. (2014). Qualitative data analysis: A methods sourcebook (3rd. ed). Thousand Oaks, CA: Sage.

Montgomery, B. L. (2017). Mapping a mentoring roadmap and developing a supportive network for strategic career advancement. SAGE Open, 7(2). 2158244017710288. https://doi.org/10.1177/2158244017710288
Morse, J. M., Barrett, M., Mayan, M., Olson, K., \& Spiers, J. (2002). Verification strategies for establishing reliability and validity in qualitative research. International Journal of Qualitative Methods, 1(2), 13-22. https://doi .org/10.1177/160940690200100202

Moses, I. (1985). Student-advisor expectation scales. Hammondville, Australia: University of Australia.

Nagy, G. A., Fang, C. M., Hish, A. J., Kelly, L., Nicchitta, C. V., Dzirasa, K., \& Rosenthal, M. Z. (2019). Burnout and mental health problems in biomedical doctoral students. CBE-Life Sciences Education, 18(2), ar27. https:// doi.org/10.1187/cbe.18-09-0198

National Academies of Sciences, Engineering, and Medicine (NASEM). (2018) Graduate STEM education for the 21st century. Washington, DC: National Academies Press.

National Academies of Sciences, Engineering, And Medicine (NASEM) (2019). The science of effective mentorship in STEMM. Washington, DC: National Academies Press. https://doi.org/10.17226/25568

National Science Foundation. (2019). Doctorate recipients from U.S. universities (NSF 20-301). Alexandria, VA.

Paglis, L. L., Green, S. G., \& Bauer, T. N. (2006). Does adviser mentoring add value? A longitudinal study of mentoring and doctoral student outcomes. Research in Higher Education, 47(4), 451-476. https://doi .org/10.1007/s11162-005-9003-2

Patton, M. Q. (1990). Qualitative evaluation and research methods (2nd ed, pp. 532). Newbury Park, CA: Sage.

Pfund, C., House, S. C., Asquith, P., Fleming, M. F., Buhr, K. A., Burnham, E. L., ... \& Sorkness, C. A. (2014). Training mentors of clinical and translational research scholars: A randomized controlled trial. Academic Medicine, 89(5), 774-782. https://doi.org/10.1097/ACM.0000000000000218

Pfund, C., Pribbenow, C. M., Branchaw, J., Lauffer, S. M., \& Handelsman, J. (2006). The merits of training mentors. Science, 311(5760), 473474. https://doi.org/10.1126/science.1123806

Porath, C. L., \& Pearson, C. M. (2010). The cost of bad behavior. Organizational Dynamics, 39(1), 64-71. https://doi.org/10.1016/j.orgdyn.2009.10.006

Ragins, B. R., Cotton, J. L., \& Miller, J. S. (2000). Marginal mentoring: The effects of type of mentor, quality of relationship, and program design on work and career attitudes. Academy of Management Journal, 43(6), 1177-1194. https://doi.org/10.5465/1556344

Ragins, B. R., Ehrhardt, K., Lyness, K. S., Murphy, D. D., \& Capman, J. F. (2017) Anchoring relationships at work: High-quality mentors and other supportive work relationships as buffers to ambient racial discrimination. Personnel Psychology, 70(1), 211-256. https://doi.org/10.1111/peps.12144

Saldana, J. (2015). The coding manual for qualitative researchers. Thousand Oaks, CA: Sage.

Scandura, T. A. (1998). Dysfunctional mentoring relationships and outcomes. Journal of Management, 24(3), 449-467. https://doi.org/10.1016/S0149 -2063(99)80068-3

Schyns, B., \& Schilling, J. (2013). How bad are the effects of bad leaders? A meta-analysis of destructive leadership and its outcomes. Leadership Quarterly, 24(1), 138-158. https://doi.org/10.1016/j.leaqua.2012.09.001

Simon, S. A., \& Eby, L. (2003). A typology of negative mentoring experiences: A multidimensional scaling study. Human Relations, 56(9), 10831106. https://doi.org/10.1177/0018726703569003

Sosik, J. J., \& Godshalk, V. M. (2000). Leadership styles, mentoring functions received, and job-related stress: A conceptual model and preliminary study. Journal of Organizational Behavior, 21(4), 365-390. https://doi. org/10.1002/(SICI)1099-1379(200006)21:4<365::AID-JOB14>3.0.CO;2-H

Sowell, R., Allum, J., \& Okahana, H. (2015). Doctoral initiative on minority attrition and completion (pp. 82). Washington, DC: Council of Graduate Schools.

Starks, H., \& Brown Trinidad, S. (2007). Choose your method: A comparison of phenomenology, discourse analysis, and grounded theory. Qualitative Health Research, 17(10), 1372-1380. https://doi.org/10.1177/ 1049732307307031

Steiner, J. F., Curtis, P., Lanphear, B. P., Vu, K. O., \& Main, D. S. (2004). Assessing the role of influential mentors in the research development of primary care fellows. Academic Medicine, 79(9), 865-872.

Steiner, J. F., Lanphear, B. P., Curtis, P., \& Vu, K. O. (2002). Indicators of early research productivity among primary care fellows. Journal of General 
Internal Medicine, 17(11), 854-860. https://doi.org/10.1046/j.1525 $-1497.2002 .10515 . x$

Stoddard, J. L. (2017). Civility matters: Overcoming workplace incivility using an interactive education intervention (Doctoral capstone). Retrieved from https://digitalrepository.unm.edu/dnp/1

Strauss, A., \& Corbin, J. (1998). Basics of qualitative research techniques. Thousand Oaks, CA: Sage.

Sverdlik, A., Hall, N. C., McAlpine, L., \& Hubbard, K. (2018). The PhD experience: A review of the factors influencing doctoral students' completion, achievement, and well-being. International Journal of Doctoral Studies, 13, 361-388. https://doi.org/10.28945/4113

Tenenbaum, H. R., Crosby, F. J., \& Gliner, M. D. (2001). Mentoring relationships in graduate school. Journal of Vocational Behavior, 59(3), 326341. https://doi.org/10.1006/jvbe.2001.1804

Tepper, B., Simon, L., \& Park, H. M. (2017). Abusive supervision. Annual Review of Organizational Psychology and Organizational Behavior, 4, 123-152. https://doi.org/10.1146/annurev-orgpsych-041015-062539

Vanderford, N. L., Evans, T. M., Weiss, L. T., Bira, L., \& Beltran-Gastelum, J. (2018). A cross-sectional study of the use and effectiveness of the
Individual Development Plan among doctoral students. F1000Research, 7. https://doi.org/10.12688/f1000research.15154.2

Welde, K. D., \& Laursen, S. L. (2008). The "ideal type" advisor: How advisors help STEM graduate students find their "scientific feet." Open Education Journal, 1(1), 49-61. https://doi.org/10.2174/ 1874920800801010049

Williams, S. N., Thakore, B. K., \& McGee, R. (2016). Coaching to augment mentoring to achieve faculty diversity: A randomized controlled trial. Academic Medicine, 91(8), 1128-1135. https://doi.org/10.1097/ ACM.0000000000001026

Wilson, Z. S., Holmes, L., deGravelles, K., Sylvain, M. R., Batiste, L., Johnson, M., ... \& Warner, I. M. (2011). Hierarchical mentoring: A transformative strategy for improving diversity and retention in undergraduate STEM disciplines. Journal of Science Education and Technology, 21(1), 148156. https://doi.org/10.1007/s10956-011-9292-5

Zhao, C., Golde, C. M., \& McCormick, A. C. (2007). More than a signature: How advisor choice and advisor behaviour affect doctoral student satisfaction. Journal of Further and Higher Education, 31(3), 263-281. https:// doi.org/10.1080/03098770701424983 